\title{
Pressure-Assisted Development and Characterization of Al-Fe Interface for Bimetallic Composite Castings: An Experimental and Statistical Investigation for a Low-Pressure Regime
}

\author{
Tayyiba Rashid 1,2,*(D), Muhammad Qaiser Saleem ${ }^{2}$ (D), Nadeem Ahmad Mufti ${ }^{2}$, Noman Asif ${ }^{2}$, M. Kashif Ishfaq ${ }^{2}$ \\ and Maham Naqvi ${ }^{3, *}$ \\ 1 Department of Industrial Engineering and Management, Faculty of Quality and Industrial Systems \\ Engineering, University of the Punjab Lahore, Lahore 54000, Pakistan \\ 2 Department of Industrial \& Manufacturing Engineering, Faculty of Mechanical Engineering, \\ University of Engineering \& Technology Lahore, Lahore 54890, Pakistan; qaiser@uet.edu.pk (M.Q.S.); \\ muftina@yahoo.com (N.A.M.); nasifie@gmail.com (N.A.); engrkashif_786@yahoo.com (M.K.I.) \\ 3 Department of Mechanical \& Industrial Engineering, New Jersey Institute of Technology, \\ Newark, NJ 07102, USA \\ * Correspondence: tayyiba.iqtm@pu.edu.pk (T.R.); mn446@njit.edu (M.N.)
}

\section{check for} updates

Citation: Rashid, T.; Qaiser Saleem, M.; Ahmad Mufti, N.; Asif, N.; Ishfaq, M.K.; Naqvi, M. Pressure-Assisted Development and Characterization of Al-Fe Interface for Bimetallic Composite Castings: An Experimental and Statistical Investigation for a Low-Pressure Regime. Metals 2021, 11, 1687. https://doi.org/10.3390/met11111687

Academic Editor: Cristiano Fragassa

Received: 3 October 2021

Accepted: 21 October 2021

Published: 23 October 202

Publisher's Note: MDPI stays neutral with regard to jurisdictional claims in published maps and institutional affiliations.

Copyright: (c) 2021 by the authors Licensee MDPI, Basel, Switzerland. This article is an open access article distributed under the terms and conditions of the Creative Commons Attribution (CC BY) license (https:/ / creativecommons.org/licenses/by/ $4.0 /)$.

\begin{abstract}
A review of the available literature indicates that the development of metal-reinforced castings present intriguing prospects but carry inherent challenges owing to differences in thermal coefficients, chemical affinities, diffusion issues and the varying nature of intermetallic compounds. It is supported that pressure application during solidification may favorably influence the dynamics of the aforementioned issues; nevertheless, not only certain limitations have been cited, but also some pressure and process regimes have not yet been investigated and optimized. This work employs the pressure-assisted approach for bimetallic steel-reinforced aluminum composite castings at a low-pressure regime and thoroughly investigates the role of three process parameters, namely pouring temperature $\left(800-900{ }^{\circ} \mathrm{C}\right)$, pressure (10-20 bars) and holding time (10-20 s), for producing sound interfaces. The Taguchi L9 orthogonal array has been employed as the Design of the Experiment, while dominant factors have been determined via analysis of variance and the grey relational analysis multi-objective optimization technique. Supplementary analysis through optical micrographs, scanning electron microscopy (SEM) and energy dispersive spectroscopy (EDS) has been utilized to quantify interfacial layer thicknesses and to study microstructural and compositional aspects of the interface. Nano-indentation tests under static and dynamic loading have also been performed for mechanical strength characterization. It has been found that uniform interfaces with verifiable diffusion are obtainable, with the pouring temperature being the most influential parameter (percentage contribution $92.84 \%$ ) in this pressure regime. The experiments performed at optimum conditions of pouring temperature, applied pressure and holding time produced a $\sim 328 \%$ thicker interface layer, $19.42 \%$ better nano-hardness and a $19.10 \%$ improved cooling rate as compared to the minimum input values of the said parameters.
\end{abstract}

Keywords: Al-Fe interface; composite castings; interfacial properties; pressure-assisted casting; cooling rate; grey relational analysis

\section{Introduction}

The continual strive for high-strength cast components has garnered a renewed research interest in the development of metal-reinforced castings (alternatively termed as dissimilar metal castings or metallic composite castings) with reportages of promising results [1,2]. In this context, a mixed metal structure of steel and aluminum alloys poses itself to be a viable tradeoff between cost and strength. Interestingly, the studies on the so-called 'die soldering' phenomenon involving iron and aluminum alloys already indicate 
the affinity existing between these two materials [3-5]. Aluminum's high affinity for Iron causes a strong reaction when $\mathrm{Al}$ melt comes into contact with ferrous material. This reaction produces iron-aluminum-silicon intermetallic compounds, which cause the cast metal to stick to it. Various studies in this regard have primarily focused on exploring the factors that are responsible for promoting interface development between the two materials. The soldering is found to be highly dependent on temperature, pre-heat temperature, die surface conditions (topography/coatings) and the chemistry of alloys [4]. The work of Kim et al. [3] and Han et al. [5,6] may be cited here for a brief background. Kim et al. [3], in their study, reported the effect of $\mathrm{Si}$ concentration (in $\mathrm{Al}$ alloy) on the formation of an $\mathrm{Al}-\mathrm{Si}-\mathrm{Fe}$ intermetallic layer on different grades of steel (H13 and 1045 steel). They concluded a higher percentage of Si results in the increased thickness of the intermetallic layer. Han et al. [5] studied the soldering for both pure aluminum as well as aluminum alloy 380 when fabricated inside a steel mold. A soldering critical temperature is suggested, at which Iron $(\mathrm{Fe})$ begins to react with aluminum $(\mathrm{Al})$ and results in the formation of an Al-rich liquid phase and solid intermetallic compounds. They purported that the critical temperature for soldering is either the solidus temperature or the coherency temperature between the two metals. In another research article, Han et al. [6] reported the liquid fraction of the solidifying metal $(\mathrm{Al})$ influences the soldering tendency and mentioned surface roughness and placement angle of the steel die to be important. A higher liquid fraction, rougher surface and placement at a certain angle were reported to favor the soldering phenomenon. In another study $[7,8]$, the addition of iron reportedly reduced the soldering tendency of aluminum alloys, but it disturbed the mechanical properties of the alloys [9-11] by making some brittle intermetallic $\beta-\mathrm{Al}_{5} \mathrm{FeSi}$. Other alloying elements, such as $\mathrm{Mn}$ and $\mathrm{Cr}$, are added to reduce the detrimental effect, and they form some compounds with iron that precipitate in the die to form a sludge.

Despite Al-Fe being an important multi-material combination, it is important to mention that the aforementioned studies and most of the other available literature, such as [12-15], are limited to hot dipping and aluminizing methodologies that may not be representative of the state-of-the-art procedures employed for producing commercial castings to produce the interfaces. Nevertheless, it is indicated from the presented literature that Iron-reinforced aluminum composites may be produced via contemporary casting routes if process parameters are carefully planned. Using this very notion, researchers have employed contemporary methods (namely, gravity die casting, High-Pressure Die Casting (HPDC), squeeze casting, diffusion-treatment and sand casting) to produce commercial castings for various material combinations, including Al-steel [16-21]. It is also worthwhile mentioning that the reported magnitude specifically for the use of pressure-assisted processes for Al-Fe composites are much less than what may be expected, especially when it is established that pressure assistance during metal casting not only enables better interfacial heat transfer coefficients but also helps produce compact/dense castings, as reported by many researchers [22-31]. Apart from the work that has reported on the die-soldering phenomenon, which inevitably occurs between $\mathrm{Al}$ and die steel in the HPDC process due to natural affinity, limited work could be found wherein high-pressure processes (such as HPDC and squeeze casting) have been purposely used to develop the Al-Fe interface as desired via controlling the process parameters. Bouayad et al. [32] used high-pressure die casting (HPDC) for producing an aluminum-steel bimetallic composite. They observed deteriorated properties of the interface in terms of air voiding and porosity at high-pressure (300 MPa) conditions and concluded that better interface thickness is achieved at less harsh conditions. For the case of the squeeze-casting process, wherein the pressure rating is typically 50-150 MPa, Bhagat [20] employed squeeze casting for producing aluminum alloy-stainless steel metal composites while experimenting with various fiber volume fractions when stainless steel was used as a mesh in the aluminum alloy matrix. They mentioned an $850^{\circ} \mathrm{C}$ metal pouring temperature, a $550{ }^{\circ} \mathrm{C}$ die pre-heating temperature and $110 \mathrm{MPa}$ pressure to be suitable parameters. It is also important to mention that the use of high pressure in metal casting processes (in general) is not without its own set of limitations. 
Ghomashchi et al. [33], while reviewing the squeeze-casting process, mentioned high cost, inadequate shape complexity, reduced die life, challenging to produce thin segments and restricted size and weight as the adverse effects of this high-pressure casting approach Kapranos et al. [34], while discussing the high-pressure casting methods, highlighted macrosegregation and non-uniform microstructure as some of the concerning issues of this high-pressure approach. In another study, Kainer et al. [35], while working with Mg alloys through the squeeze-casting route, also reported process limitations in terms of reduced flexibility for part geometry in addition to a higher cost. Specifically, in the context of multi-material Al-Fe castings, for the already-mentioned work of Bhagat [20], although a $40 \%$ volume fraction reportedly resulted in higher tensile strength of the composite in comparison to that reported for an aluminum alloy (without reinforcement), the composites were still reported to have lower strength (in general) to what had been predicted by the rule of mixtures. They attributed it to the generation of a weak interface as a result of a 'more-than-desirable' reaction between fiber and matrix materials in the interface. They also cited limitations in generating uniform interface thickness and observance of large scatter in the values. The need for the optimization of squeeze-casting process parameters was also cited to overcome the issues faced in interface development. Understandably, they employed the higher-pressure values that are typical of a squeeze-casting process, and follow-up work of any sort that employed pressure assistance in lower value regime(s) for the Al-Fe interface has not yet been covered in the available literature. An additional factor that is revealed by reviewing the aforementioned literature reported for $\mathrm{Al}-\mathrm{Fe}$ in high-pressure processes is that the focus of most studies has been on the metallurgical characteristics of the interface, whereas parametric correlations and quantification of the roles of process parameters are lacking. Presently, the interface characterization for certain mechanical attributes (e.g., nano-hardness, etc.) and the establishment of parametric relationships are needed to identify parameters that are critical to achieving the desired interfaces and properties in the context of Al-Fe multi-material composite castings.

To sum up the above-presented literature review, it is clear that pressure assistance during the metal-casting process is favorable (in general) because it makes a high rate of cooling and compactness of casting possible; at the same time, it may also be deduced that very high pressures that are typical for the well-established high-pressure die casting and squeeze-casting processes may present certain limitations in terms of tool life, cost, handling of design complexity and unwanted reactions, etc. In this context, a pertinent research question is generated as to if a lower-pressure regime may provide the beneficial effects of pressure assistance while overcoming the issues associated with the typically employed high-pressure processes. It is also to be appreciated that investigation and development of multi-material Al-Fe interface at low pressures would inevitably translate into better die life and cost dynamics of the process due to the less harsh process/pressure conditions. Correspondingly, the need to develop an interface for the important material combination of Al-Fe, when considered in tandem with the identified research gaps (the lack of reported work for Al-Fe in low-pressure regime despite its potential, the lack of established parametric correlations, which may be needed to develop sound Al-Fe interfaces, and the lack of mechanical characterization aspects of interface), presents an opportunity to investigate along these lines.

This work investigates the role of three process parameters, namely pressure, pouring temperature and time for application of pressure (holding time), for producing sound interfaces in a low-pressure regime. An Al-5\% Si alloy has been used with mild steel reinforcement. Interfacial layer thicknesses have been quantified along with the study of its microstructural, compositional and nano-hardness aspects. The evaluation of nanohardness is considered, realizing that in view of the formed intermetallics, the interface may be better characterized by the nano-scale hardness parameter than microhardness. The analysis is supplemented with superior optimization algorithms, such as grey relational analysis (GRA), which is a multi-response optimization technique used to identify the best-quality characteristics through the determination of the optimum conditions of the 
input parameters [36]. Discussions are supplemented with an analysis of cooling rates as calculated for the experiments to better understand and explain the ensuing process dynamics.

\section{Materials and Methods}

\subsection{Experimental Details}

A cylindrical shaped Al-5\% Si alloy specimen $(\Phi 60 \times \mathrm{L}=70 \mathrm{~mm})$ reinforced by three equally spaced vertical mild steel rods placed at $120^{\circ}$ apart (when viewed in cross-section) was cast using an 80-ton vertical hydraulic press. Instead of using a mesh structure, rods were employed for reinforcement so as to focus on interface development at different experimental conditions while preventing any potential adversities arising from complicated flow patterns (had mesh been used). Six K-type thermocouples interfaced with the data acquisition system were inserted into pre-defined locations to capture thermal profiles along radius and height. The thermocouples were connected to a Data Logger and ultimately linked to a computer system. Prior to placement in die (made of D2), the mild steel rods $(\Phi 5 \times \mathrm{L}=60 \mathrm{~mm}$ ) were pickled with a $90 \%$ hydrochloric acid solution, followed by immersion in iso-propyl alcohol to clean any rust (if present) on the surface, as used by others $[37,38]$. For the pouring, the melt was prepared in a pit furnace. The die was pre-heated to $500{ }^{\circ} \mathrm{C}$ using an external heating system, and the pouring pressure was applied and maintained for a specified time (holding time). Afterwards, the bimetal casting was allowed to cool naturally at room temperature. Three settings of each input parameter-pouring temperature, applied pressure and holding time-were used for experimentation. The input parameter values were chosen based on trial experiments conducted prior to actual experimentation. The Taguchi L9 standard orthogonal array design was used as the DOE in this work, as has been adopted by others [39-41]. The choice was thus guided by the works of Patel et al. [39], who used the Taguchi L9 orthogonal array to optimize three input variables-squeeze pressure, die temperature and pouring temperature-for a high-pressure squeeze-casting process for an LM20 alloy; Adke [40], who, while working with the die-casting method, also employed the Taguchi L9 approach and improved the cycle time by optimizing the process parameters; and Apparao et al. [41], who also employed Taguchi L9 orthogonal array for process optimization. It is pertinent to note that the Taguchi L9 orthogonal array is followed by grey relational analysis (GRA). GRA, which is a powerful analysis technique, and the use of Taguchi orthogonal array is an established approach that helps to arrive at the optimum settings of parameters with a lesser number of experiments, as may be required for full factorial experiments [42].

The approach is associated with reducing the cost and time of experimentation without compromising the reliability of the findings. Correspondingly, the approach is reported to be an attractive option and is a widely used tool by engineers and scientists around the globe [43]. Section 2.2 contains some information for its use in this work. Figure 1 provides the schematic of the specimen as placed in the die, providing essential details, such as locations of thermocouple placements and size of the specimen produced, etc. The actual images for the experimental setup and die are given in Figure 2. Table 1 presents the details of the variables and constants. For post-experimentation analysis, samples for the microstructure, SEM analysis and mechanical characterization were extracted from the castings. Figure 3 shows the schematic (Figure $3 a, b$ ) and the actual cast component (Figure 3c), and the locations the specimens were taken from for post-experimental analysis marked. 


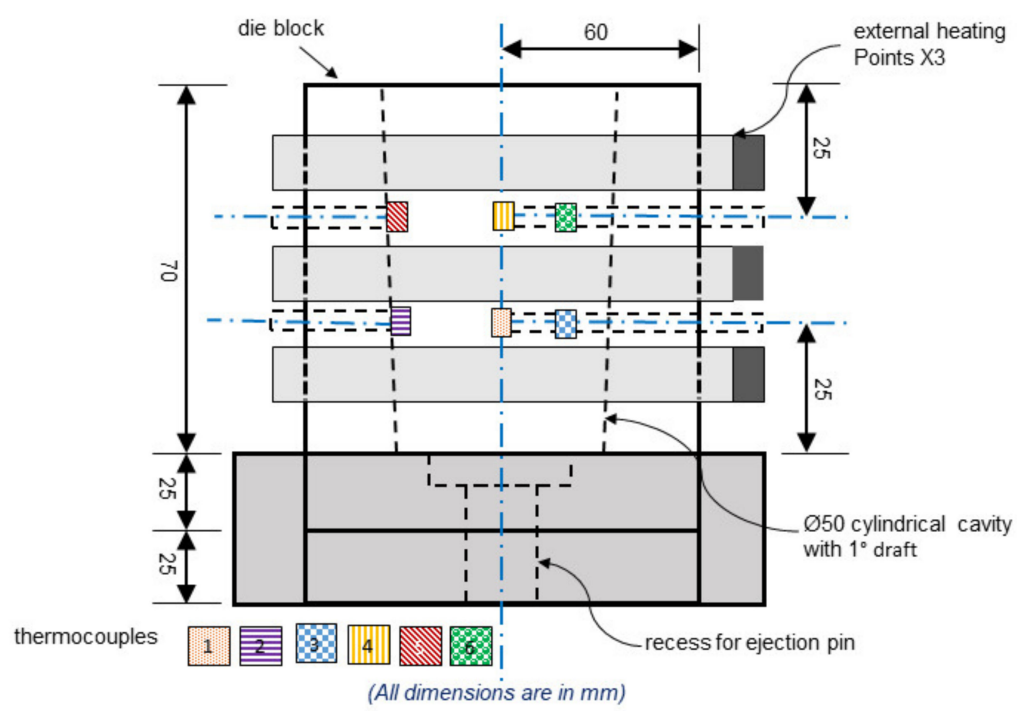

Figure 1. Schematic of the die.

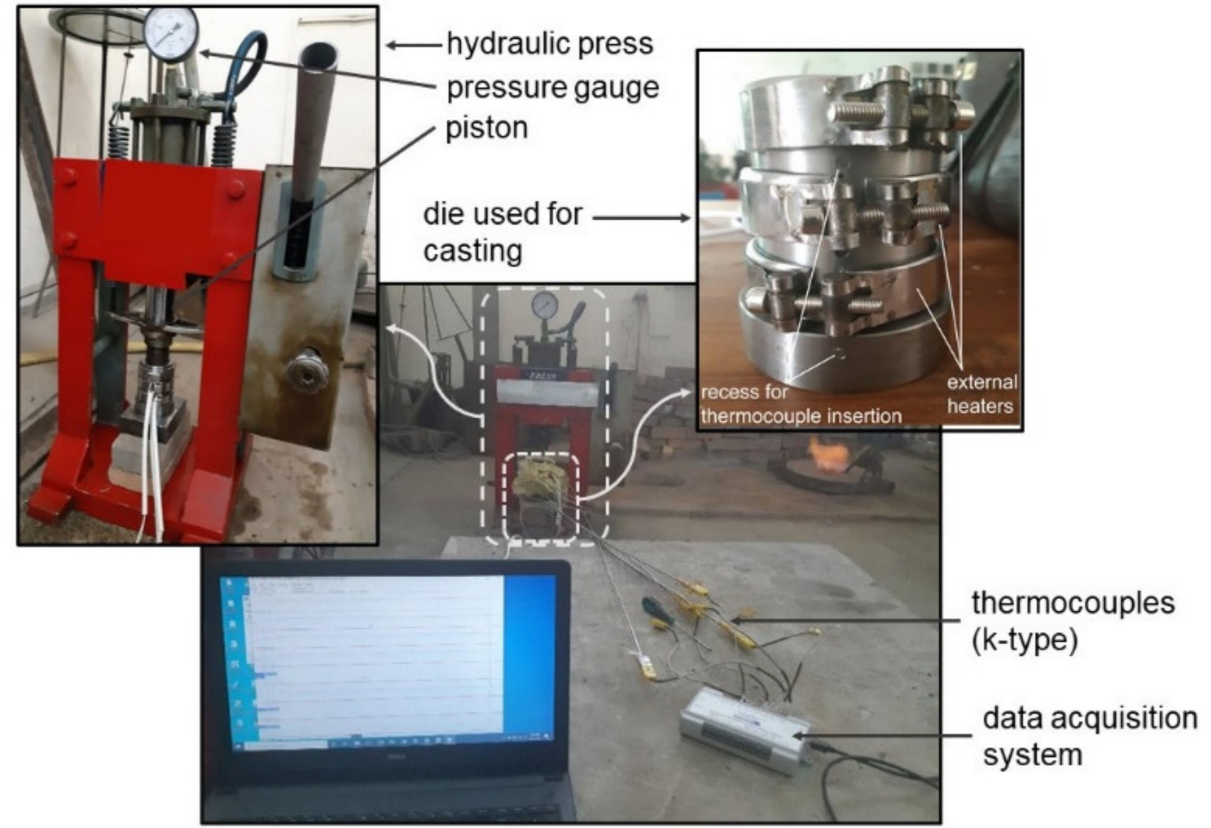

Figure 2. Experimental setup.

Table 1. Design of experiment.

\begin{tabular}{cccc}
\hline Variables & Level 1 & Level 2 & Level 3 \\
\hline Pouring temperature $\left({ }^{\circ} \mathrm{C}\right)$ & 800 & 850 & 900 \\
Applied pressure $(\mathrm{Bar})$ & 10 & 15 & 20 \\
Holding time $(\mathrm{Sec})$ & 10 & 15 & 20 \\
\hline & Constants & & Matrix \\
\hline & Melt Mass 1.1 kg & Aluminum-5\% Silicon & $\begin{array}{c}\text { Temperature } \\
\left(500{ }^{\circ} \mathrm{C}\right)\end{array}$ \\
\hline
\end{tabular}



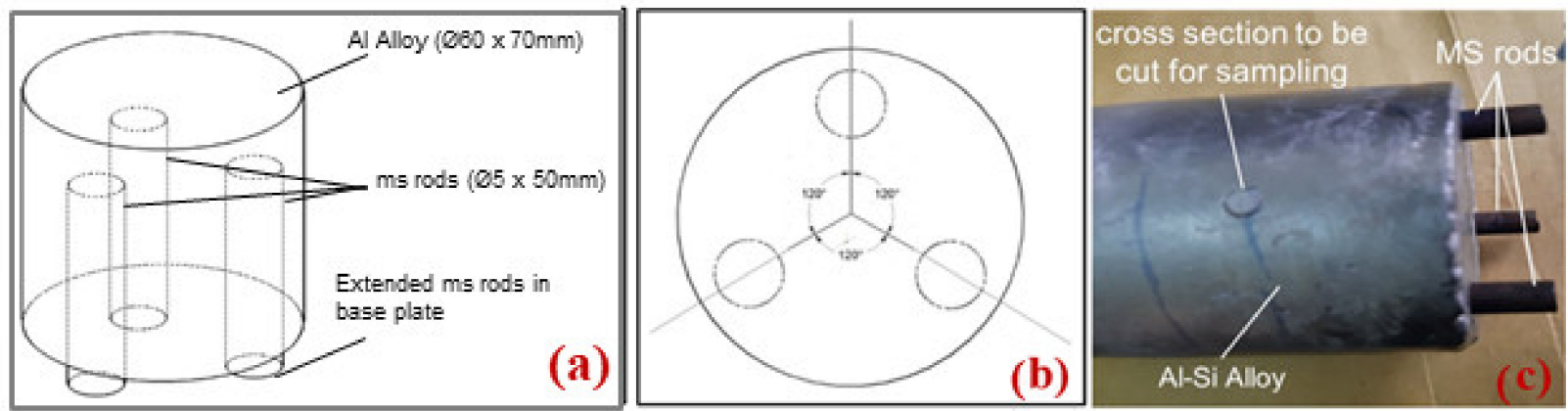

Figure 3. (a,b) Schematics demonstrating the length and location of the pins and (c) the actual cast component.

Optical micrographs (Leica DMI 500 microscopic machine, Wetzlar, Germany) were taken at a magnification of $500 \times$ to examine the microstructure and to evaluate the thickness of the diffusion layer. Interface SEM (Inspect S-50 of Thermo Fisher Scientific, Hillsboro, OR, USA) images were taken at a magnification of $3000 \times$ for an in-depth examination of compositional and microstructural details. Samples for microstructure and SEM were prepared using standard metallographic procedures. For mechanical characterization, nanoindentation testing (NANO INDENTER VR IIs machine, supplied by Nano Instruments Ltd., Oak Ridge, TN, USA) was conducted for the interface. A loading and unloading rate of $200 \mathrm{mN} / \mathrm{min}$ and an acquisition rate of $10 \mathrm{~Hz}$ were utilized. A record of the penetration depth was made over a complete loading cycle with a maximum load of $100 \mathrm{mN}$ using depth-sensing indentation. Three samples were tested in each testing condition to ensure repeatability, and the average is reported herein. The complete research methodology is highlighted in Figure 4.

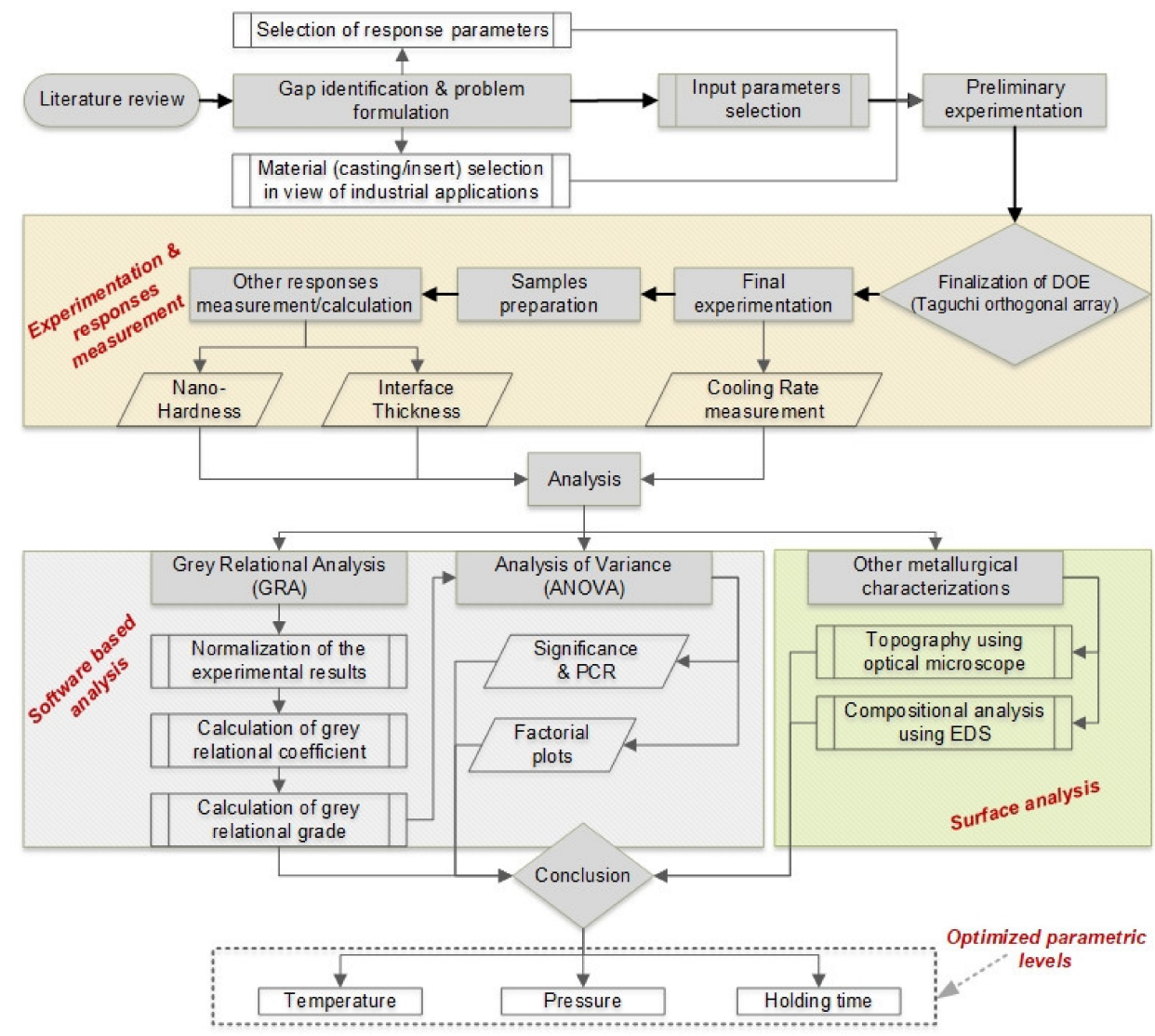

Figure 4. Research methodology. 


\subsection{Statistical Analysis}

Statistical analysis was carried out for the obtained results using statistical software Minitab 19.1. The analysis of variance (ANOVA) was performed at a confidence level of $95 \%$ in order to find out the significant input parameters and their percentage contribution for selected responses. Additionally, grey relational analysis (GRA) was employed for the multi-objective optimization of the casting parameters. This analysis is a suitable multi-step method [44] used to measure the degree of approximation (among sequences) through grey relational grade $(G R G)$. The main objectives taken for this work were the maximization of interface thickness (IT), nano-level hardness $(\mathrm{H})$ and the cooling rate $\left(\mathrm{R}_{\mathrm{c}}\right)$. Correspondingly, the "larger-the-better" was taken as the criterion. A brief explanation of the analysis employed in the current work is explained herein. Firstly, data were normalized. The range for normalization is kept between 0.00 to 1.00 , with the best-normalized results equal to 1.00 [45]. Equation (1) is used for this purpose.

$$
x_{i}(k)=\frac{y_{i}(k)-\operatorname{miny}_{i}(k)}{\max _{i}(k)-\operatorname{miny}_{i}(k)}
$$

where $x_{i}(k)$ is the normalized value for the kth observation after data pre-processing, $y_{i}(k)$ is the original sequence, while $\operatorname{miny}_{i}(k)$ and $\operatorname{maxy}_{i}(k)$ are the smallest and largest experimental values of particular responses from the design matrix, respectively. $i$ is the data number (observations), which, in our design matrix, is from 1 to 9 . Once the data are normalized, it is followed by calculating the grey relational coefficients $(G R C)$, which highlight the relation between the desired/ideal results and the actual normalized results. The final step involved is the determination of the grey relational grade $(G R G)$, which gives a single grade for response variables [46]. Equation (2) is used for GRC calculations. GRG values range from 0 to 1 .

$$
\begin{aligned}
\mu_{i}(k) & =\frac{\delta_{\min }+\mathrm{m} \delta_{\max }}{\delta_{0 i}(k)+m \delta_{\max }} \\
\delta_{0 i}(k) & =\left\|x_{0}(k)-x_{i}(k)\right\|
\end{aligned}
$$

$\mu_{i}(k)$ is the grey relational coefficient, $m$ is the identification/distinguishing coefficient that is usually set to 0.5 [47]. $\delta_{\min }$ and $m \delta_{\max }$ are the minimum and maximum deviations of each response variable, respectively. $\delta_{0 i}(k)$ is called the deviation sequence, which is calculated by Equation (3). This determines the deviation of the normalized data from the ideal value of 1.00. On the other hand, Equation (4) [48] is used for GRG calculation by taking the average of GRCs.

$$
G R G_{i}=\frac{1}{n} \sum_{k=1}^{n} w_{i} \mu_{i}(k) \sum_{k=1}^{n} w_{i=1}
$$

GRG values range from 0 to 1 . The highest value of $G R G$ infers the ultimate combination of eminent casting process characteristics.

\section{Results}

The experimentation results for the nine experiment runs are provided in Table 2. The succeeding sections contain the detailed analysis and discussions. 
Table 2. Experimentation results.

\begin{tabular}{|c|c|c|c|c|c|c|}
\hline Exp. No & $\begin{array}{c}\text { Pouring Temperature } \\
\mathrm{T} \\
\left({ }^{\circ} \mathrm{C}\right)\end{array}$ & $\begin{array}{c}\text { Applied Pressure } \\
\text { P } \\
\text { (bar) }\end{array}$ & $\begin{array}{l}\text { Holding Time } \\
\text { Ht } \\
\text { (s) }\end{array}$ & $\begin{array}{l}\text { Interface } \\
\text { Thickness } \\
\text { IT }(\mu \mathrm{m})\end{array}$ & $\begin{array}{c}\text { Hardness } \\
\text { H } \\
\text { (GPa) }\end{array}$ & $\begin{array}{c}\text { Cooling Rate } \\
R_{\mathrm{c}} \\
\left({ }^{\circ} \mathrm{C} / \mathrm{s}\right)\end{array}$ \\
\hline 1 & 800 & 10 & 10 & 9.8 & 9.01 & 1.78 \\
\hline 2 & 800 & 15 & 15 & 11.0 & 9.25 & 1.94 \\
\hline 3 & 800 & 20 & 20 & 13.8 & 9.58 & 2.09 \\
\hline 4 & 850 & 10 & 15 & 18.9 & 9.96 & 1.86 \\
\hline 5 & 850 & 15 & 20 & 28.5 & 10.03 & 1.98 \\
\hline 6 & 850 & 20 & 10 & 30.7 & 10.14 & 2.09 \\
\hline 7 & 900 & 10 & 20 & 38.0 & 10.27 & 1.93 \\
\hline 8 & 900 & 15 & 10 & 40.9 & 10.45 & 2.07 \\
\hline
\end{tabular}

\subsection{Interface Characterization}

\subsubsection{Microscopic and Compositional Analysis}

The thickness of the interface for the resultant casting has been measured for all the experiments via micrographs. The representative micrographs for all the nine experiment conditions are presented in Figure 5 for comparison purposes. As can be seen from the micrographs, interface thickness increases when the higher values of parameters (pressure and pouring temperature) are used. An average interface thickness of $\sim 42$ microns achieved at higher values of the above-mentioned parameters is around $328 \%$ more than $\sim 9.8$ microns obtained at the least values of process parameters employed herein. In essence, the improved interface thickness values are indicative of the increased diffusion as temperature and pressure values increase.

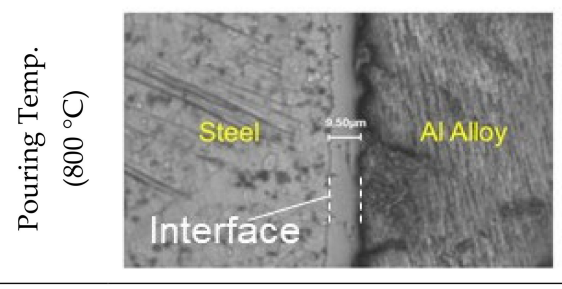

10 bar, 15 s

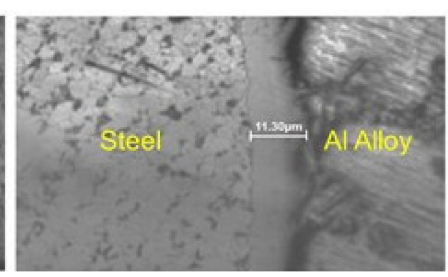

15 bar, $20 \mathrm{~s}$

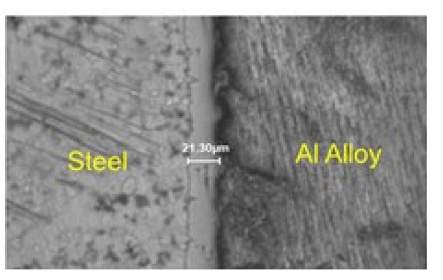

20 bar, $10 \mathrm{~s}$

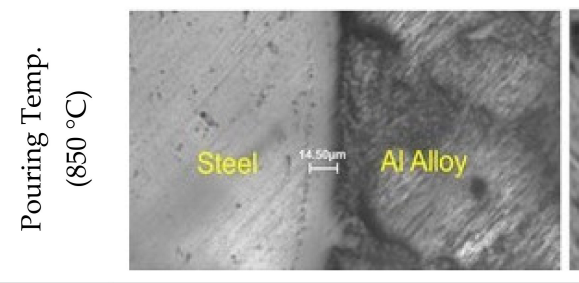

10 bar, $20 \mathrm{~s}$

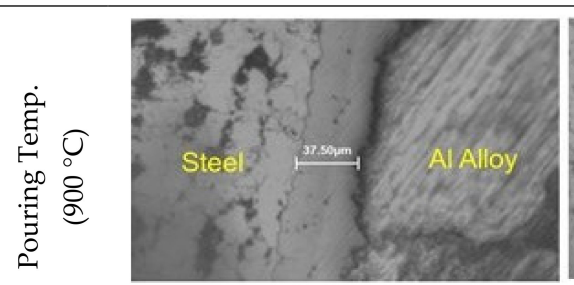

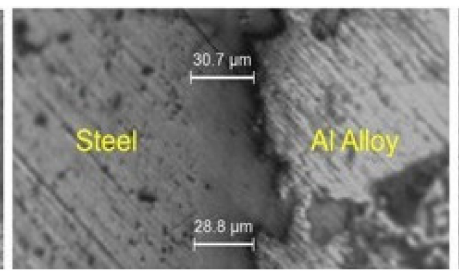

15 bar, $10 \mathrm{~s}$

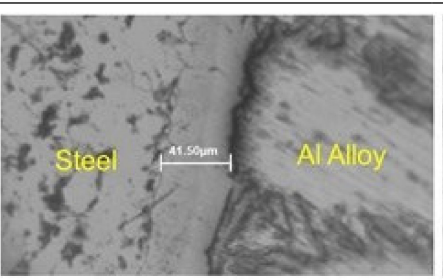

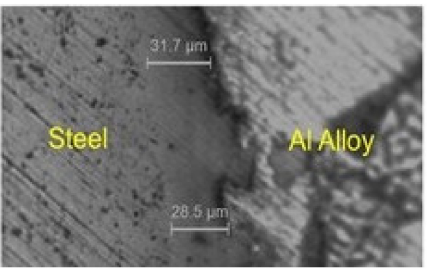

20 bar, $15 \mathrm{~s}$

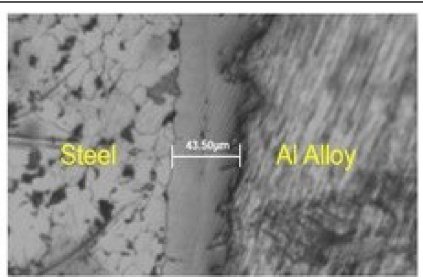

Figure 5. Microstructures of the interface region of bimetals made at different temperatures and pressures.

These results, wherein a higher temperature caused more interface thickness in general, are effectively supported by Fick's law for diffusion [49] when reviewed in conjunction 
with the diffusivity relation. It can thus be shown that diffusion is a function of temperature. At higher temperatures, atoms/molecules gain more mobility in liquids as well as solids. A higher initial concentration of a particular element may cause its diffusion into other solids. Fick's first law has expressed this diffusional flow mathematically, as shown in Equation (5).

$$
J_{x}=-D \frac{\delta C}{\delta X}
$$

where $J_{x}$ is the flow rate of the diffusing species in the direction $X$ based on the gradient $\left(\frac{\delta C}{\delta X}\right)$. Here, $\mathrm{D}$ is termed as the diffusion coefficient (also known as diffusivity). The following expression in Equation (6) is used to calculate diffusivity $D$.

$$
D=D_{o} e^{-\frac{Q}{R T}}
$$

$D_{o}$, is the pre-exponential coefficient, $Q$ is the activation energy per mole of diffusing species, and $R$ is the universal gas constant. The $T$ is the absolute temperature. This equation shows that the diffusion coefficient is based on temperature, and as the reciprocal of temperature $(1 / T)$ decreases, diffusion increases. The increase in temperature triggers diffusion to progress more swiftly, resulting in thicker diffusion layers at the interface. Correspondingly, a higher temperature is seen to result in better values.

In terms of pressure, the results show the role of pressure to be favorable as well. Here too, for a pouring temperature of $900{ }^{\circ} \mathrm{C}$, the thickness at 20 bar is around $10 \%$ higher compared to the one obtained at 10 bar even when a relatively lesser holding time has been employed. An additional and visible advantage of the pressure-assisted process is the generation of a nearly uniform interface for each case, as can be seen in Figure 5. More specifically, when compared with other reported work, such as by Chen et al. [50], who employed nearly 200-times higher pressure in the compound-forging process to fabricate Al-steel bimetal, it is observed that the achieved interface here is much thicker than the already reported work. In their work the interface thickness of $7.9 \mu \mathrm{m}$ was achieved when the initial temperature of the steel ball was kept at $900{ }^{\circ} \mathrm{C}$ and the applied pressure was $503 \mathrm{MPa}$. Incidentally, the average interface thickness achieved in the current study ranges from $9.8 \mu \mathrm{m}$ to $42.0 \mu \mathrm{m}$, which is much higher than that achieved by the compound forging. The possible reason for the higher interface obtained herein is that a higher pressure employed in the reported work would increase the rate of heat transfer, which would result in quicker heat loss from the components, thus not allowing much time for the constituents to diffuse. However, this is not the case here, where the lesser values of pressure would inevitably result in a relatively lesser rate of heat loss, which is expected to give a reasonable amount of time for the constituents to diffuse up to a certain distance. Additionally, the forging process is a solid-state process for which the rate of diffusion would be lesser than the current process where the aluminum alloy has been poured in a liquid state.

As no previous work reporting on aluminum steel bimetallic development in the investigated pressure regime was found, a direct comparison of the current work with previously reported results may not be possible. However, an indirect comparison can still be presented to appreciate the improvements obtained herein. When compared with reported work by Jiang et al. [51] on compound casting, a much higher maximum interface thickness has been achieved in the current work. The maximum interface thickness of around $30 \mu \mathrm{m}$ is reported for Al-steel bimetallic, which is $\sim 28.57 \%$ less than what has been achieved with the pressure-assisted approach herein. Bouayad et al. [26] reported air voids and porosity within the interfaces of their aluminum-steel bimetallic composite produced through the HPDC process at high pressures. They attributed it to quick cooling and low-temperature condition of the process, which would contribute to difficulty in achieving appropriate diffusion. No such observance has been found in the current work. In a recent work by Bakke et al. [52], the $\mathrm{Al}_{7} \mathrm{SiMg}$ /steel bimetallic interface produced at a much lower pressure (1.2 bar using Low-Pressure Die Casting (LPDC)) than what has been employed in the presented work was reported to be non-uniform and porous and 
needed further heat treatment to enhance its properties. The generation of sound interfaces in current work shows the suitability of the currently investigated low-pressure regime of 10-20 bar.

Even for the case of other systems, such as $\mathrm{Al}-\mathrm{Cu}$, it is deduced that very high pressure may not necessarily be resulting in very thick interfaces. Liu et al. [29], while producing bimetal component $(\mathrm{Al}-\mathrm{Cu})$ through the squeeze-casting process, observed an increase in the thickness of the reaction layer as the temperature was increased (due to the higher diffusion at elevated temperature); however, an increase in squeeze pressure resulted in a decreasing trend of the overall thickness. The highest value obtained for thickness was about $80 \mu \mathrm{m}$ at $30 \mathrm{MPa}$ pressure, which further decreased when pressure was increased to $110 \mathrm{MPa}$. As stated earlier, the higher rate of heat transfer during solidification that is associated with higher pressure values is most likely the reason. The above analysis indicates the importance of the lower pressure regime in producing an appropriate level of interface thickness enabled by the balance between pressure and available time for diffusion to occur. Table 2 provides a summary of the results for interface thickness in graphical form.

To confirm the diffusion of materials at the interface and to compare the effects of input parameters on interface constituents, an EDS analysis was performed. Figure $6 a, b$ presents the elemental profile plots/line scan for all the parametric conditions. Here, the EDS scans of the interface validate the presence of the primary constituents of the two metals involved in this composite. This line scan also highlights the percentage of variation of $\mathrm{Al}, \mathrm{Si}$ and $\mathrm{Fe}$ at the interface region. Within the interface, the concentration of the primary element diminishes as we move to the opposite side of the base metal/alloy that constituent belongs to. Another interesting observation is that more $\mathrm{Al}$ diffuses into the interface in comparison to steel, which could be attributed to the smaller size of $\mathrm{Al}$ atoms compared to Fe atoms [53]. It is pertinent to specify that the percentage of constituents is also influenced by the experimental conditions. Higher pressure and temperature values are seen to favor more aluminum diffusion into the interface than $\mathrm{Fe}$, as reported in the literature [54]. Correspondingly, at higher values of these parameters (say Experiment 9), the percentage of aluminum increases with the decrease in the Fe percentage. The possible reason for this is the larger dissemination of molten aluminum into steel at a higher temperature and pressure, resulting in a rather compact and uniform interface thickness.

\subsubsection{Quantification for the Role of Parameters for Interface Thickness}

In order to understand the role of different parameters, the main effect plots for interface thickness are provided in Figure 7 . The results are supplemented by analysis of variance (ANOVA), as demonstrated in Table 3, for their percentage contribution to the outputs. Here, the pouring temperature is proven to be the most significant parameter at a $95 \%$ confidence level with a percentage contribution of $92.84 \%$. As can be seen from the plots, both pressure and pouring temperature positively correlate with the thickness, whereas holding time in the investigated regime does not seem to be very influential. The percentage contribution of holding time is only $1.35 \%$, and the line is almost horizontal in the main effect plot. The value of the mean interface thickness changes from $27 \mu \mathrm{m}$ to $24 \mu \mathrm{m}$ when the holding time is increased from $10 \mathrm{~s}$ to $15 \mathrm{~s}$. Similarly, it increases to $26.7 \mu \mathrm{m}$ with the rise in holding time to $20 \mathrm{~s}$. Considering that the overall variation in its value is only up to $\sim 12.5 \%$ (considering max. and min. interface thicknesses of 27 and 24 microns), whereas the overall change in the input variable of holding time is 100\% (10 to $20 \mathrm{~s}$ ); therefore, the pattern may not be considered indicative of any appreciable change, especially when the factor has been determined to be statistically non-significant as well. 

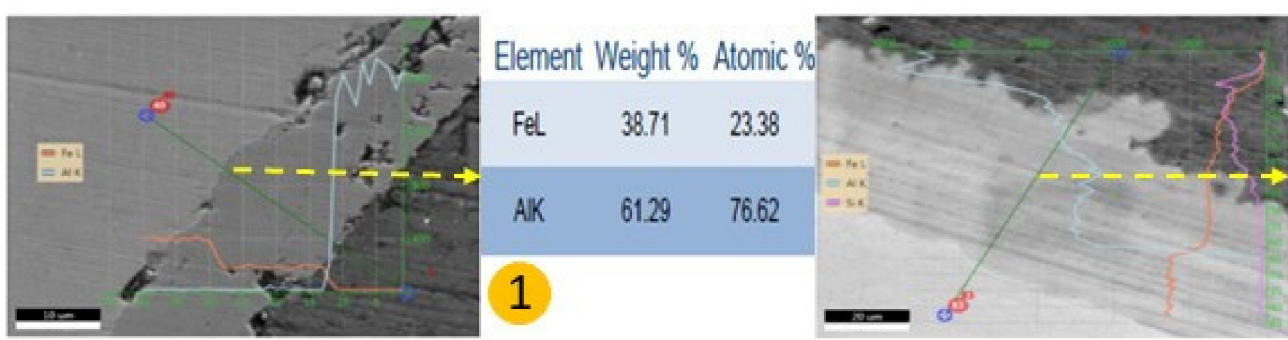

Element Weight \% Atomic \%

$\begin{array}{lll}\text { Fel. } & 30.03 & 17.23\end{array}$

AK $\quad 62.68 \quad 74.45$

SK $\quad 7.29 \quad 8.31$

2
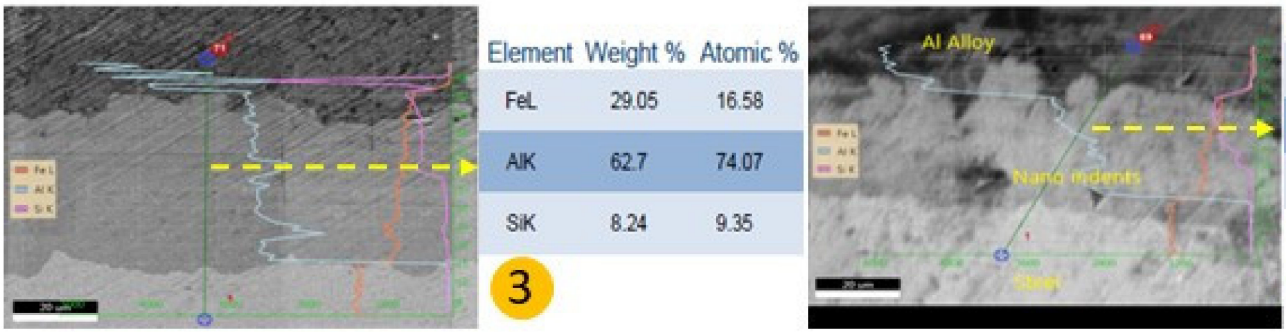

Element Weight $\%$ Atomic \%

\begin{tabular}{|lll|}
\hline AIK & 66.76 & 77.71 \\
\hline SiK & 6.47 & 7.24 \\
\hline
\end{tabular}

4

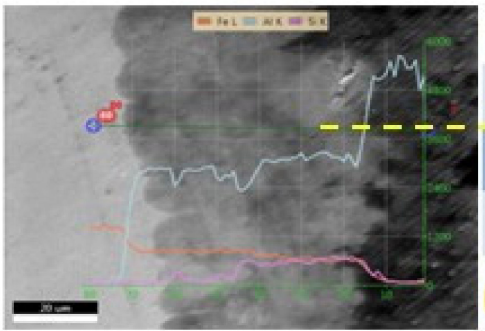

Element Weight $\%$ Atomic $\%$

\begin{tabular}{ccc} 
FeL & 22.77 & 12.52 \\
\hline AK & 68.67 & 78.13 \\
\hline SK & 8.56 & 9.35 \\
\hline 5 & & \\
\hline
\end{tabular}

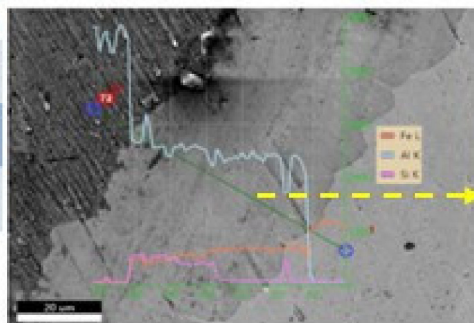

Element Weight \% Atomic \% $\mathrm{Fe}$

AK $\quad 69.28 \quad 79.17$
SK

6

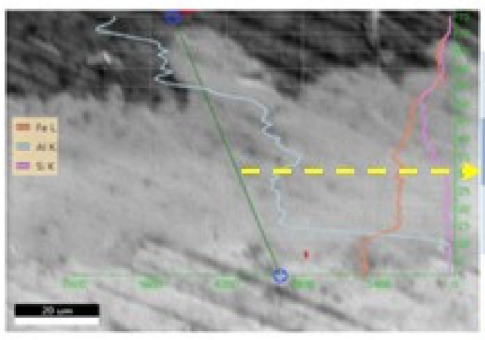

Element Weight \% Atomic \%

\begin{tabular}{|ccc|} 
Fel & 23.93 & 1323 \\
\hline AIK & 70.02 & 60.12 \\
\hline SIK & 6.05 & 6.65 \\
\hline
\end{tabular}

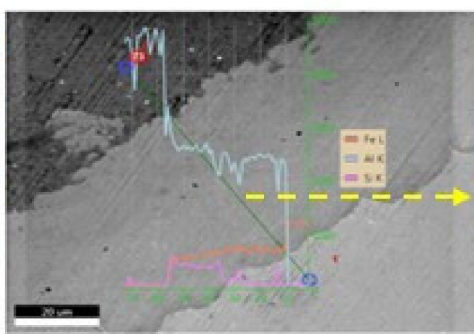

Element Weight \% Atomic \%

\begin{tabular}{lll} 
FeL & 21.64 & 11.81 \\
\hline AK & 72.02 & 81.32 \\
\hline SIK & 6.34 & 6.87
\end{tabular}

7

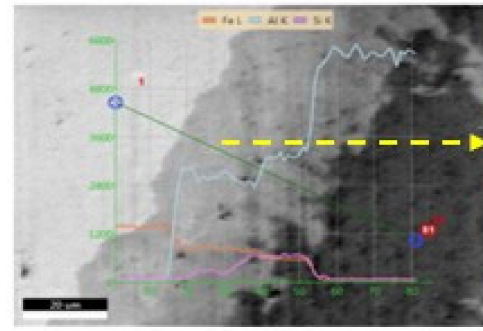

\begin{tabular}{ccc} 
Element Weight \% & Atomic \% \\
FeL & 19.9 & 10.75 \\
\hline AIK & 73.36 & 82.02 \\
\hline SiK & 6.73 & 7.23 \\
\hline
\end{tabular}

9

(a)

Figure 6. Cont. 

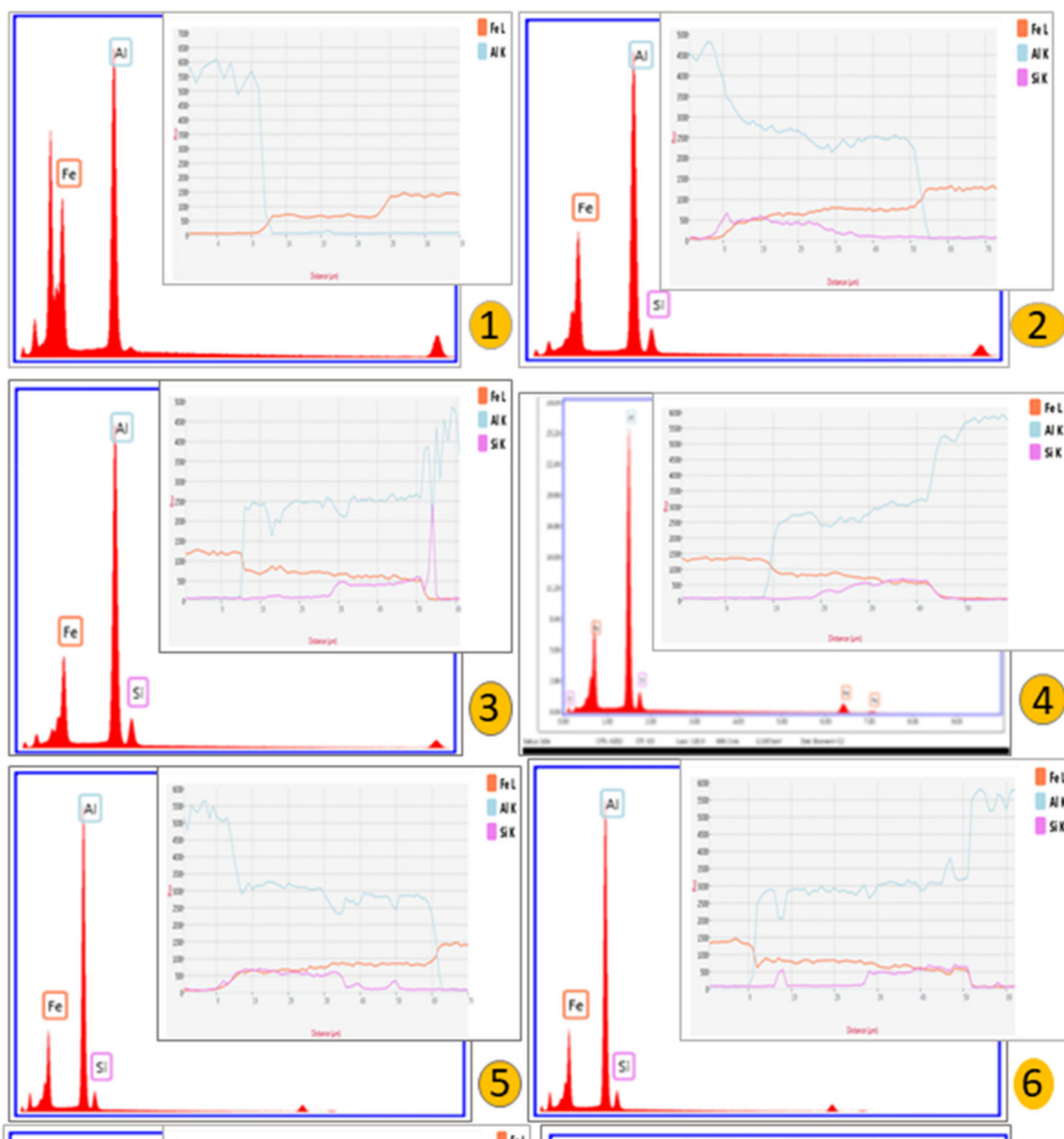

3

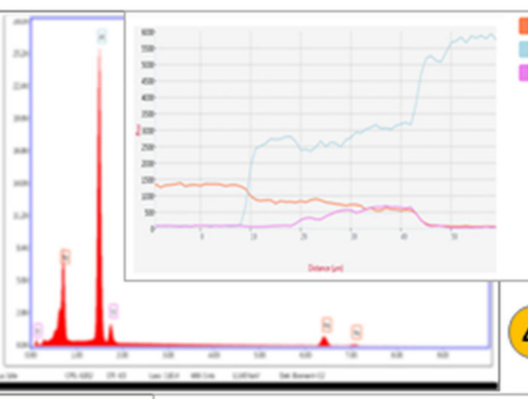

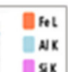
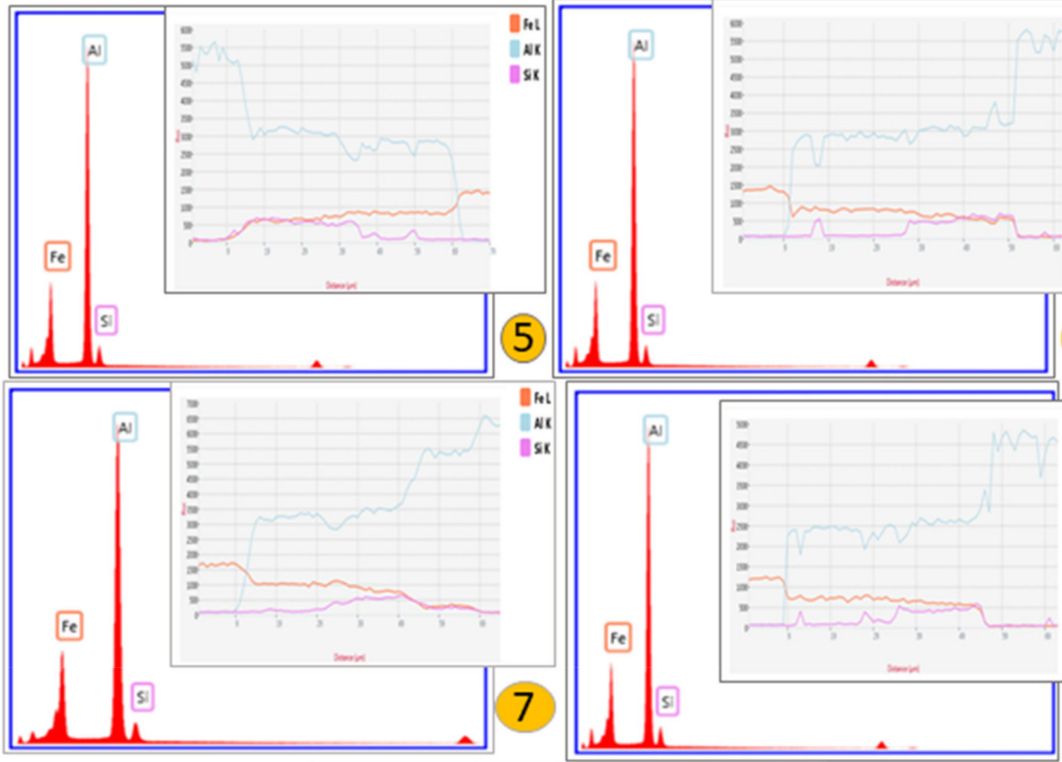

4

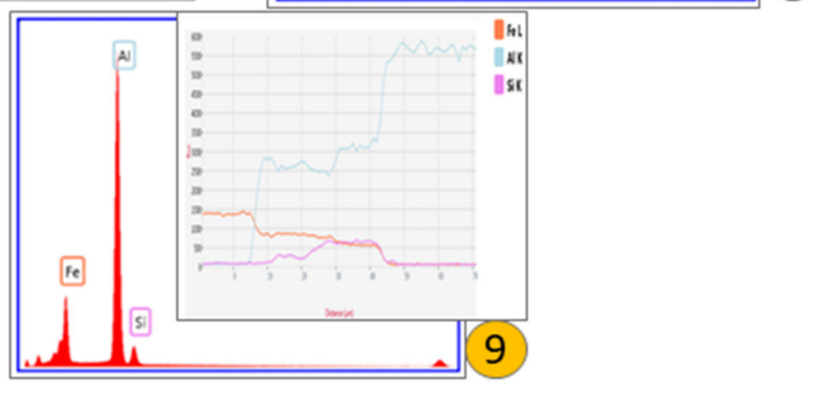

(b)

Figure 6. (a) SEM micrographs and EDS analysis of the interface of the aluminum/steel bimetallic composite (for all experiments). (b) SEM elemental percentage variation of the interface of the aluminum/steel bimetallic composite (for all experiments). 


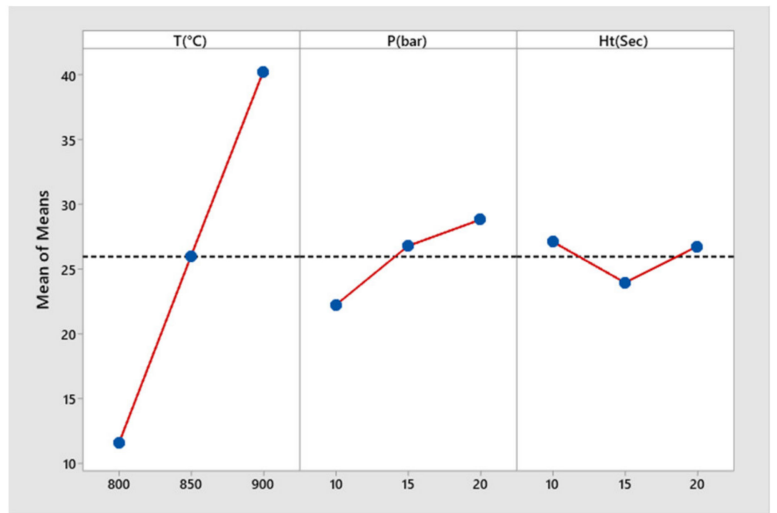

Figure 7. Main effect plots for interface thickness.

Table 3. ANOVA table for interface thickness.

\begin{tabular}{cccccccc}
\hline Source & DF & Seq SS & Adj SS & Adj MS & F-Value & $p$-Value & Contribution \\
\hline $\mathrm{T}\left({ }^{\circ} \mathrm{C}\right)$ & 2 & 1241.31 & 1241.31 & 620.654 & 135.48 & 0.007 & $92.84 \%$ \\
$\mathrm{P}(\mathrm{bar})$ & 2 & 68.55 & 68.55 & 34.274 & 7.48 & 0.118 & $5.13 \%$ \\
$\mathrm{Ht}(\mathrm{Sec})$ & 2 & 18.00 & 18.00 & 9.001 & 1.96 & 0.337 & $1.35 \%$ \\
Error & 2 & 9.16 & 9.16 & 4.581 & & $0.69 \%$ \\
Total & 8 & 1337.02 & & & & $100.00 \%$ \\
& & & R-sq: $99.31 \%$ & R-sq (adj): $97.26 \%$ & & \\
\hline
\end{tabular}

In order to gain further insight, the interaction plot (Figure 8) shows that pressure and holding time may have a joint effect on the composite's interface thickness. This may be related to the way they could influence the diffusion phenomenon. When pressure is applied for an extended period of time, it may result in increased diffusion of constituents. The beneficial effect of pressure and holding time for the diffusion bonding has been reported elsewhere as well [55]. When pressure is applied for a longer period of time, it helps break the oxide layer that otherwise prevents the diffusion of aluminum and steel. Another important impact is the reduction in the gaps in the diffusion layer, making it more compact and refined.

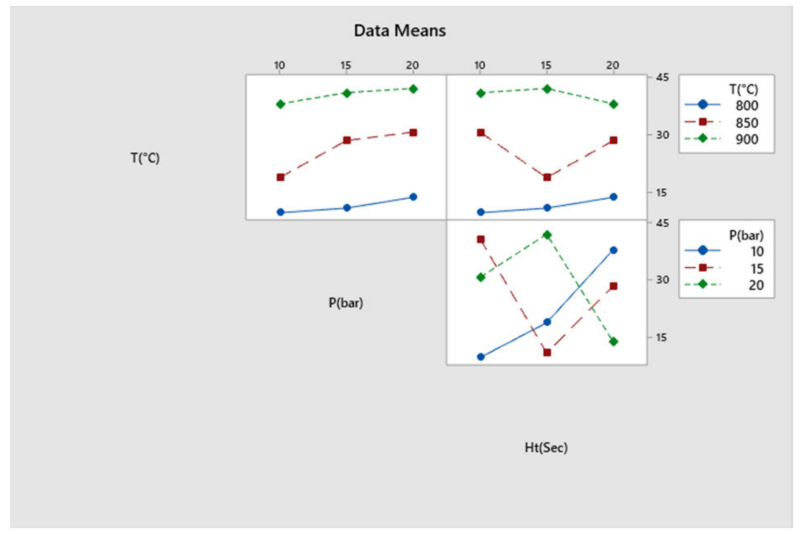

Figure 8. Interaction plots for interface thickness.

\subsubsection{Nano-Hardness}

The nano-hardness values obtained for all nine experiments have been shown in Table 2. It can be seen that maximum hardness $(10.76 \mathrm{GPa})$ is obtained at the interface in Experiment 9, which is in line with the results obtained for interface thickness. If compared to Experiment 1 conditions, where we have the smallest values of all processing parameters, an improvement of $19.42 \%$ is highlighted. Another important aspect is that the range of 
hardness achieved at the interface is higher than the hardness of an individual $\mathrm{Al}$ alloy $(1.50 \mathrm{GPa})$ and steel $(2.50 \mathrm{GPa})$. It is not uncommon for the interface to develop higher nanohardness than the base materials. The work by Jiang et al. [56], where magnesium-steel bimetal was developed, reported higher nano-hardness values $(11.1 \mathrm{GPa})$ of the interface layer as compared to the hardness of magnesium (1.1 GPa) and steel matrixes (4.2 GPa). It is important to mention that $\mathrm{Al}$ melt has the capability to spread homogeneously over the iron insert, thus initiating the diffusion of elements $(\mathrm{Fe}, \mathrm{Al}$ and $\mathrm{Si})$ at the interface. The higher values of hardness for the developed interface may be associated with the presence of typical intermetallics found in this layer, such as $\mathrm{Fe}_{2} \mathrm{Al}_{5}, \tau_{10}-\mathrm{Al}_{9} \mathrm{Fe}_{4} \mathrm{Si}_{3} \mathrm{FeAl}_{3}$, $\mathrm{Al}_{12} \mathrm{Mg}_{17}$ and $\mathrm{Al}_{12} \mathrm{Mg}_{17}$. It is obvious that the types of intermetallic layers produced and their thicknesses play critical roles in obtaining materials with desirable performances. In a reported work [57], wherein the interaction between a solid iron rod and molten $\mathrm{Al}$ was investigated, intermetallics, such as $\mathrm{FeAl}_{3}$ and $\mathrm{Fe}_{2} \mathrm{Al}_{5}$, were identified through $\mathrm{XRD}$ analysis within the interface layer. Additionally, the $\mathrm{Fe}_{2} \mathrm{Al}_{5}$ layer thickness was found to be larger than the $\mathrm{FeAl}_{3}$ layer. In another work, Jiang et al. [58] also observed intermetallics, such as $\mathrm{Fe}_{2} \mathrm{Al}_{5}, \tau_{10}-\mathrm{Al}_{9} \mathrm{Fe}_{4} \mathrm{Si}_{3}, \mathrm{FeAl}_{3}, \tau_{5}-\mathrm{Al}_{8} \mathrm{Fe}_{2} \mathrm{Si}$ and $\tau_{6}-\mathrm{Al}_{4.5} \mathrm{FeSi}$, which could be the reason for the higher nano-hardness $(10.49 \mathrm{GPa})$ for the interface reported in their work. The literature survey reveals that the intermetallics, such as $\mathrm{Fe}_{2} \mathrm{Al}_{5}$ and $\mathrm{FeAl}_{3}$, formed in the interface layer are brittle [52]. The general inverse relationship of brittle materials and hardness is already established, which explains the higher nano-hardness values within the interface. Vendra and Rabiei [59] investigated the diffusion of iron and aluminum and observed the presence of brittle $\mathrm{Fe}_{2} \mathrm{Al}_{7} \mathrm{Si}$ phase. Mathew et al. [60] reported that the presence of Fe makes the interface brittle, and at the same time, hardness is increased as compared to the base alloy while studying the effect of Fe intermetallic on nanomechanical properties of $\mathrm{Al}-7 \% \mathrm{Si}$ alloys (produced in graphite crucible inside Carbolite high-temperature chamber furnace). It is important to mention that the aforementioned intermetallics in $\mathrm{Al}$-ssteel interfaces are reported in work employing other processes as well and may therefore be considered an outcome of the diffusion reactions occurring for these two materials. Cao et al. [61], in their work on aluminum steel joints produced through the welding process, analyzed mechanical characteristics using the nano-indentation technique. The intermetallics produced are $\mathrm{Fe} 2 \mathrm{Al} 5, \mathrm{FeAl}$ and $\mathrm{Fe} 3 \mathrm{Al}$ with varying hardness values of $16.11 \mathrm{GPa}, 9.48 \mathrm{GPa}$ and $4.13 \mathrm{GPa}$. The variation is reported to be influenced by the type of intermetallics produced. The typical intermetallics found in the Al-Fe interface, their mechanical attributes of being brittle and hard and their reported nano-hardness values, which are comparable to the ones obtained in current work, effectively explain the current findings and confirm that the current results conform with the available literature in this regard.

A comprehensive load-displacement curve at the interface developed at all experimental conditions is shown in Figure 9. It is evident from the graph that with the increase in the interface's hardness, the penetration of the indenter is reduced in general, indicating the increasing strength of the interface. A slight anomaly in this regard is only observed for Experiment 5, wherein the extent of penetration, as depicted in the same Figure, is not that much as it may be expected. This minor variation may be attributed to an experimental error; however, in general, the pattern of the load vs. displacement graph (for the calculation of nano-hardness) correlates. It can be seen that at the same load conditions, the interface developed at more favorable conditions is able to better resist deformation, indicating a harder interface. The least indenter penetration $(0.95 \mu \mathrm{m})$ has been achieved for the interface produced at the highest level of parameters, which is $26.92 \%$ less when compared to the maximum penetration $(1.3 \mu \mathrm{m})$ achieved with the least parametric levels. 


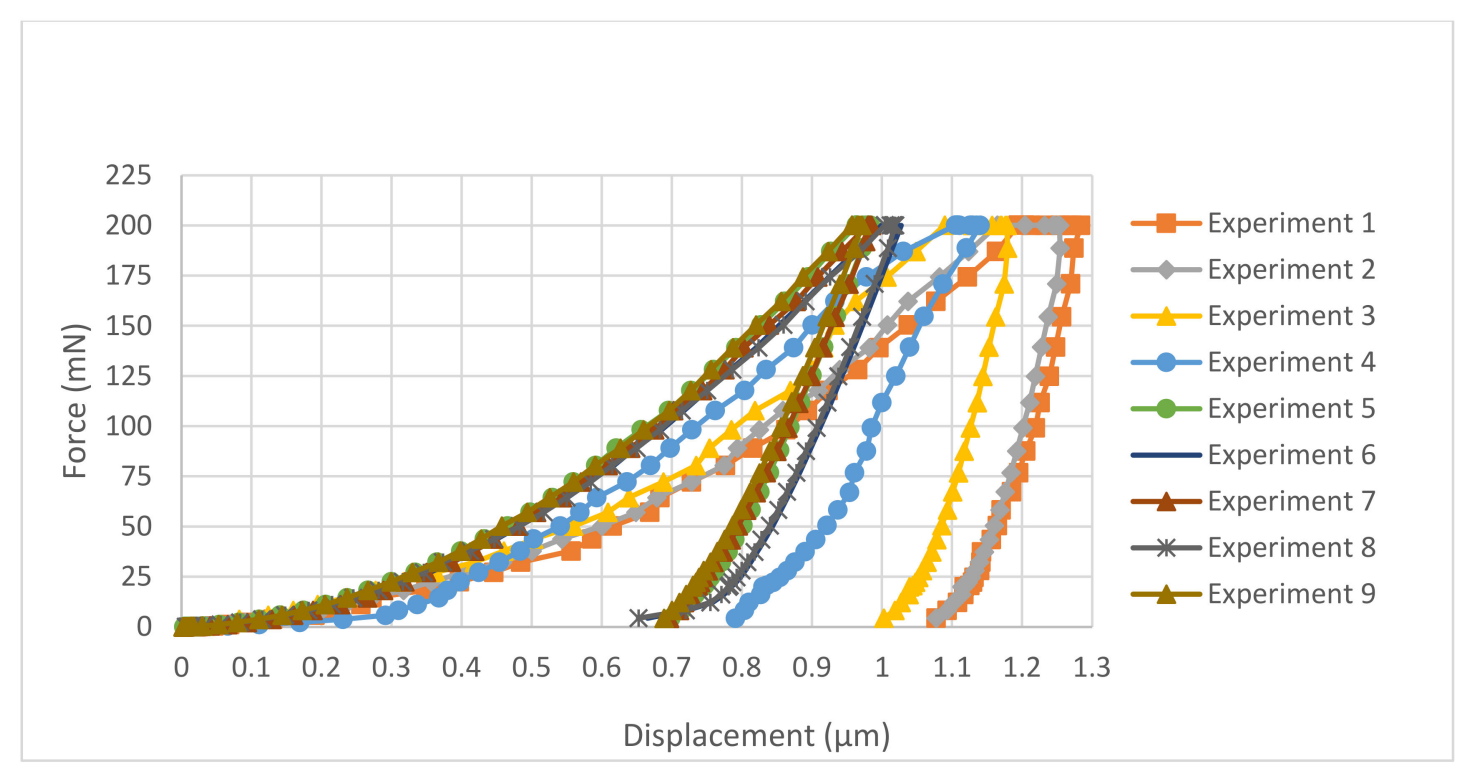

Figure 9. Load vs. displacement graph.

3.1.4. Quantification for the Role of Parameters for Nano-Hardness and Cooling Rate

Figure 10 shows the main effect plots for nano-level hardness, wherein an increasing trend for hardness values with an increased temperature. At higher temperatures, the diffusion of $\mathrm{Al}$ into steel is increased and improves the formation of intermetallics, resulting in increased hardness values. The increase in pressure and holding time has also shown a higher hardness value. The ANOVA table (Table 4) shows that with a $p$-value of 0.009 , the temperature is the most significant parameter and has the highest percentage contribution value $(88.28 \%)$. Pressure is the second significant factor, with a percentage contribution of $10.02 \%$, whereas holding time is the least influential, with a percentage contribution of $0.94 \%$. The mean value of hardness changes from $9.87 \mathrm{MPa}$ to $9.99 \mathrm{MPa}$ with the rise in holding time from 10 to $15 \mathrm{~s}$. The hardness value drops to $9.96 \mathrm{MPa}$ with a further increase in holding time to $20 \mathrm{~s}$. Therefore, the overall change is just $0.9 \%$ when holding time is increased to twice the initial value, i.e., $10 \mathrm{~s}$. That is why the trend line of change in the mean value of hardness does not show any significant impact on the output value.

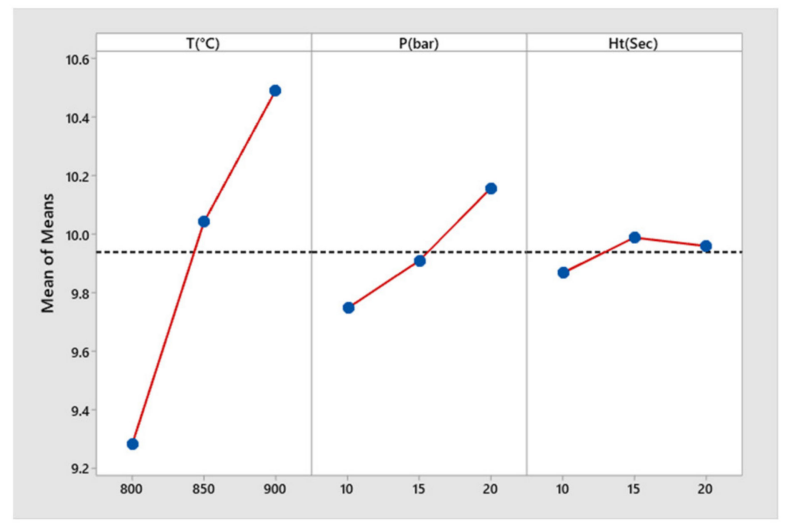

Figure 10. Main effects plot for nano-hardness. 
Table 4. ANOVA table for nano-hardness.

\begin{tabular}{cccccccc}
\hline Source & DF & Seq SS & Adj SS & Adj MS & F-Value & $p$-Value & Contribution \\
\hline $\mathrm{T}\left({ }^{\circ} \mathrm{C}\right)$ & 2 & 2.25398 & 2.25398 & 1.12699 & 116.18 & 0.009 & $88.28 \%$ \\
$\mathrm{P}(\mathrm{bar})$ & 2 & 0.25579 & 0.25579 & 0.12789 & 13.18 & 0.071 & $10.02 \%$ \\
$\mathrm{Ht}(\mathrm{Sec})$ & 2 & 0.02400 & 0.02400 & 0.01200 & 1.24 & 0.447 & $0.94 \%$ \\
Error & 2 & 0.01940 & 0.01940 & 0.00970 & & $100.00 \%$ \\
Total & 8 & 2.55317 & & & & \\
& & & R-sq: $99.24 \%$ & R-sq(adj): $96.96 \%$ & & \\
\hline
\end{tabular}

Further, as was observed for interface thickness, the combined effect of pressure and holding time is also evident in the interaction plot in Figure 11.

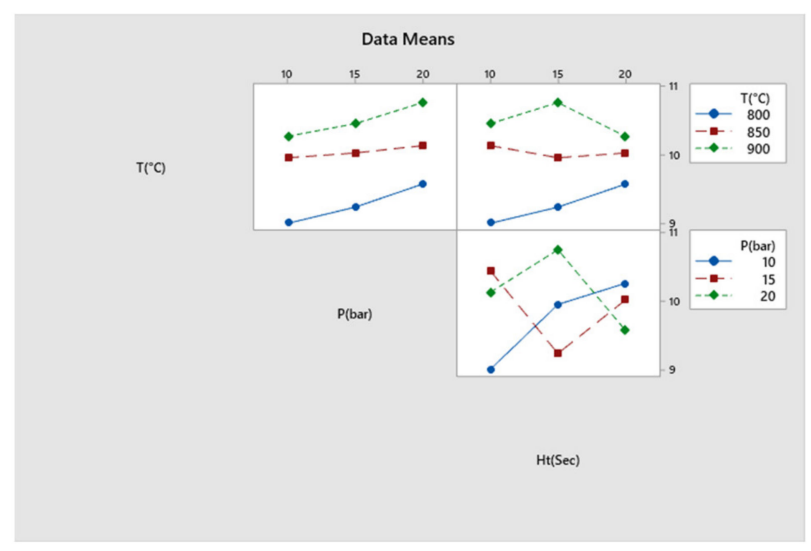

Figure 11. Interaction plots for nano-hardness.

The results for nano-hardness are best explained when supplemented by cooling rates calculated for the experiments. It was observed that Experiment 9, wherein pressure and temperature were at their maximum values (of the investigated set), resulted in the highest cooling rate. Table 2 shows the values of the different cooling rates calculated for all nine experiments. The cooling rate obtained for Experiment 9 is around 20\% higher than Experiment 1, where pressure and temperature were at their least. In Experiment 9, the higher available temperature gradient has been made possible by the higher pouring temperature along with the applied pressure, which, in its own independent capacity, has been reported to increase the interfacial heat transfer coefficient during solidification $[27,62,63]$. All of this results in accelerated heat transfer from the casting. Correspondingly, the microstructure that is reported to be a function of cooling rate [64-66] will also be refined, which, in turn, results in the betterment of mechanical properties; therefore, the interdependency of mechanical properties and microstructure on the cooling rate is established [67]. The same could be inferred here wherein higher values of nano-indentation have been achieved at these conditions. Importantly, as can be seen from Table 2, the three highest cooling rates (Experiment 9,6 and 3) are all obtained when the applied pressure was at the highest value (20 bar), not only supporting the given explanation but also hinting towards the role of pressure in developing accelerated cooling rates. If we compare this work with reported literature (where higher values of pressure have been used), with the application of pressure, an increase in the cooling rate has been reported [66].

This is further confirmed when ANOVA (Table 5) and the main effect plot (Figure 12) are performed for the cooling rates. Here, the pressure is the most contributing parameter with a value of $81.98 \%$ and is statistically significant at a $95 \%$ confidence level. 
Table 5. ANOVA table for the cooling rate.

\begin{tabular}{cccccccc}
\hline Source & DF & Seq SS & Adj SS & Adj MS & F-Value & $p$-Value & Contribution \\
\hline $\mathrm{T}\left({ }^{\circ} \mathrm{C}\right)$ & 2 & 0.015268 & 0.015268 & 0.007634 & 5.38 & 0.157 & $14.29 \%$ \\
$\mathrm{P}(\mathrm{bar})$ & 2 & 0.087589 & 0.087589 & 0.043794 & 30.89 & 0.031 & $81.98 \%$ \\
Ht $(\mathrm{Sec})$ & 2 & 0.001154 & 0.001154 & 0.000577 & 0.41 & 0.711 & $1.08 \%$ \\
Error & 2 & 0.002836 & 0.002836 & 0.001418 & & $2.65 \%$ \\
Total & 8 & 0.106845 & & & \\
& & & R-sq: $97.35 \%$ R-sq(adj): $89.38 \%$ & & \\
\hline
\end{tabular}

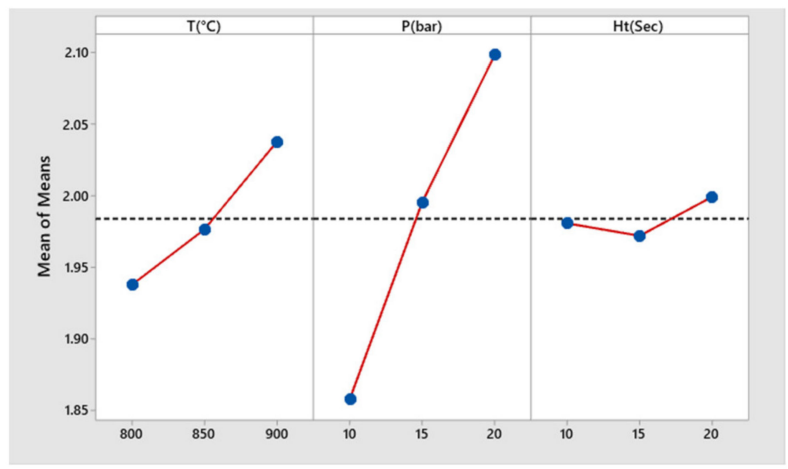

Figure 12. Main effect plot for the cooling rate at different experimental conditions.

It is also important to note that the cooling rate's pattern does not entirely match the pattern obtained for nano-hardness results. For example, the two cooling rates (for Experiments 3 and 6) that immediately lag the best cooling rate of Experiment 9 do not result in the second and third highest nano-hardness values. This can also be explained; at higher cooling rates, a possibly adverse effect could be that a very quick temperature drop may not allow enough time for diffusion to properly take place. Interestingly, both of these experiment conditions ( 3 and 6) have a higher pressure value (which is a statistically significant parameter for cooling rate), but the corresponding pouring temperatures are lower $\left(800\right.$ and $\left.850^{\circ} \mathrm{C}\right)$. The temperature has been determined to be a statistically significant parameter for interface thickness. Accordingly, at these lower pouring temperatures, despite obtaining relatively higher cooling rates, relatively lesser interface thickness and nano-indentation hardness have been achieved. Experiment 9 has both the parameters at their favorable values, so not only the highest cooling rate but also the interface thickness and nano-indentation are at their best.

It is also important to note that temperature in combination with pressure and holding time affect the overall cooling rate of the composite casting, as shown in Figure 13.

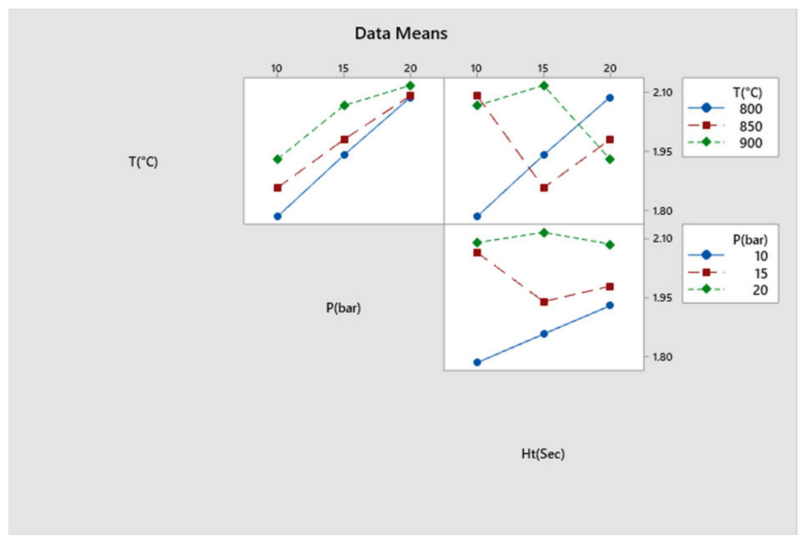

Figure 13. Interaction plots for the cooling rate at different experimental conditions. 


\subsection{Multi-Objective Optimization Using GRA}

The optimization has been carried out for the development of the sound interface. Table 6 contains the normalizing and deviation sequence, GRC and GRG. The highest grade shows the optimal parametric setting for the process. The highest GRG value is obtained for Experiment 9, where the temperature is $900^{\circ} \mathrm{C}$, the pressure is $20 \mathrm{bar}$, while the holding time is $15 \mathrm{~s}$.

Table 6. Normalizing sequence and deviation sequence.

\begin{tabular}{ccccccccccc}
\hline \multirow{2}{*}{ Exp. No } & \multicolumn{3}{c}{ Normalizing Sequence } & \multicolumn{3}{c}{ Deviation Sequence } & \multicolumn{3}{c}{ Grey Relational Coefficient } \\
\cline { 2 - 10 } & $\mathbf{I T}$ & $\mathbf{H}$ & $\mathbf{R}_{\mathbf{c}}$ & $\mathbf{I T}$ & $\mathbf{H}$ & $\mathbf{R}_{\mathbf{c}}$ & $\mathbf{I T}$ & $\mathbf{H}$ & $\mathbf{R}_{\mathbf{c}}$ & - \\
\hline 1 & 0.0000 & 0.0000 & 0.0000 & 1.0000 & 1.0000 & 1.0000 & 0.3333 & 0.3333 & 0.3333 & 0.3333 \\
2 & 0.0373 & 0.1342 & 0.4693 & 0.9627 & 0.8658 & 0.5307 & 0.3418 & 0.3661 & 0.4851 & 0.3977 \\
3 & 0.1242 & 0.3251 & 0.9102 & 0.8758 & 0.6749 & 0.0898 & 0.3634 & 0.4256 & 0.8477 & 0.5456 \\
4 & 0.2826 & 0.5432 & 0.2202 & 0.7174 & 0.4568 & 0.7798 & 0.4107 & 0.5226 & 0.3907 & 0.4413 \\
5 & 0.5807 & 0.5823 & 0.5873 & 0.4193 & 0.4177 & 0.4127 & 0.5439 & 0.5449 & 0.5478 & 0.5455 \\
6 & 0.6491 & 0.6438 & 0.9220 & 0.3509 & 0.3562 & 0.0780 & 0.5876 & 0.5840 & 0.8651 & 0.6789 \\
7 & 0.8758 & 0.7205 & 0.4372 & 0.1242 & 0.2795 & 0.5628 & 0.8010 & 0.6414 & 0.4704 & 0.6376 \\
8 & 0.9658 & 0.8253 & 0.8459 & 0.0342 & 0.1747 & 0.1541 & 0.9360 & 0.7411 & 0.7645 & 0.8139 \\
9 & 1.0000 & 1.0000 & 1.0000 & 0.0000 & 0.0000 & 0.0000 & 1.0000 & 1.0000 & 1.0000 & 1.0000 \\
\hline
\end{tabular}

\subsubsection{ANOVA for GRA}

After ranking, an ANOVA is also performed for GRG values to find the most significant parameter(s). It can be seen from Table 7 that temperature and pressure, with $\mathrm{p}$-values less than 0.05 , are significant for GRG. The percentage contribution for temperature is $66.98 \%$, while for pressure, it is $31.07 \%$. The main effect plot for GRG is provided in Figure 14. The response table (Table 8) shows the levels that result in the highest GRG values. Temperature and pressure at level 3 with the holding time at level 2 show the highest GRG. GRG for all the experimental conditions, along with the rank, is shown in Figure 15.

Table 7. ANOVA table for GRG.

\begin{tabular}{cccccccc}
\hline Source & DF & Seq SS & Adj SS & Adj MS & F-Value & $p$-Value & Contribution \\
\hline $\mathrm{T}\left({ }^{\circ} \mathrm{C}\right)$ & 2 & 0.238796 & 0.238796 & 0.119398 & 52.78 & 0.019 & $66.98 \%$ \\
$\mathrm{P}($ bar $)$ & 2 & 0.110781 & 0.110781 & 0.055390 & 24.49 & 0.039 & $31.07 \%$ \\
$\mathrm{H}_{\mathrm{t}}(\mathrm{s})$ & 2 & 0.002422 & 0.002422 & 0.001211 & 0.54 & 0.651 & $0.68 \%$ \\
Error & 2 & 0.004524 & 0.004524 & 0.002262 & & $1.27 \%$ \\
Total & 8 & 0.356523 & R-sq: $98.73 \%$ R-sq(adj): $94.92 \%$ & & $100.00 \%$ \\
& & &
\end{tabular}

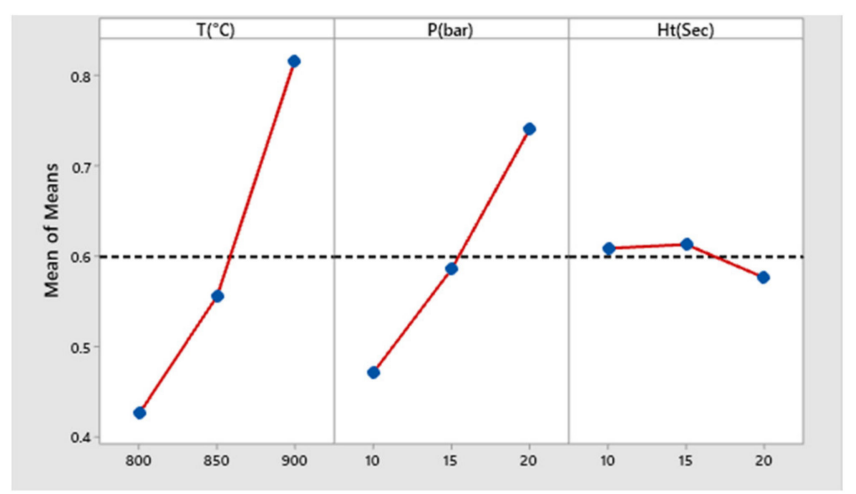

Figure 14. Main effects plots for GRG. 
Table 8. Response table for GRG.

\begin{tabular}{cccccc}
\hline Level & $\mathbf{1}$ & $\mathbf{2}$ & $\mathbf{3}$ & Delta & Rank \\
\hline $\mathrm{T}\left({ }^{\circ} \mathrm{C}\right)$ & 0.4255 & 0.5552 & 0.8172 & 0.3916 & 1 \\
$\mathrm{P}(\mathrm{bar})$ & 0.4708 & 0.5857 & 0.6130 & 0.2707 & 2 \\
$\mathrm{Ht}(\mathrm{Sec})$ & 0.6087 & 0.6130 & 0.5762 & 0.0368 & 3 \\
\hline
\end{tabular}

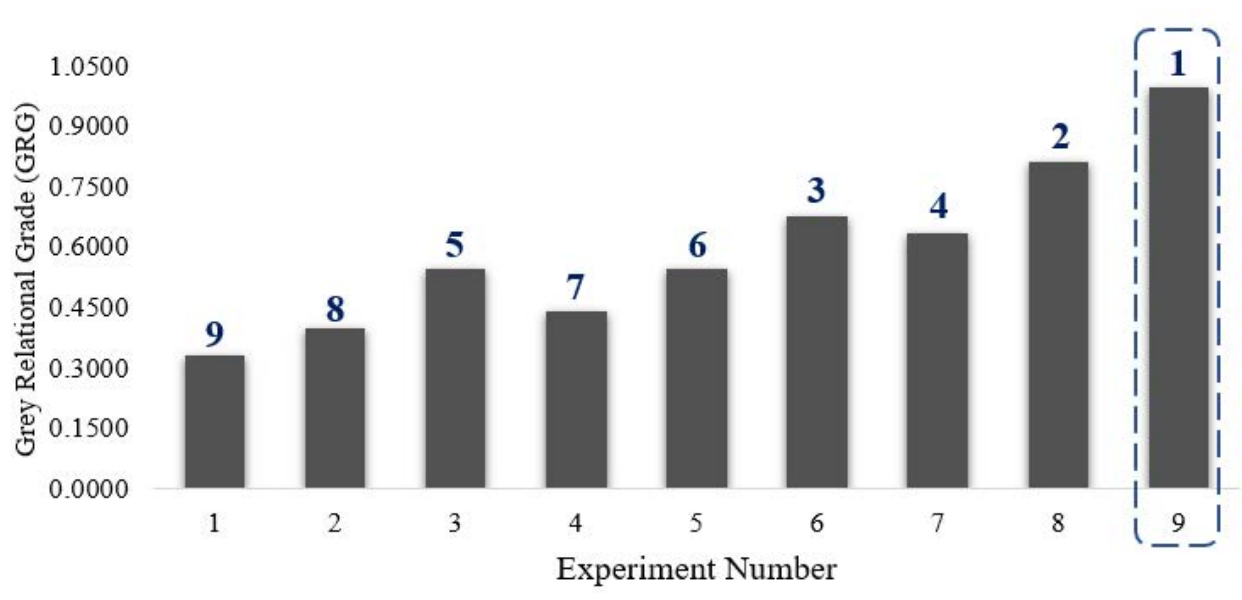

Figure 15. Grey relational grade for all experiments.

\subsubsection{Confirmation Tests}

A confirmatory experiment was performed for interface thickness, nano-hardness and cooling rate based on the optimization conducted herein. The response table for the means (Table 8) highlights levels at which all three parameters will give optimal results. From this table, the levels with the highest mean value are selected; thus, the optimal parametric levels are a temperature of $900^{\circ} \mathrm{C}$, a pressure of $20 \mathrm{bar}$, and a holding time of $15 \mathrm{~s}$. Based on this suggested parametric setting, confirmatory experimentation was carried out. The results from the initial experimental matrix and the confirmatory experiment are highlighted in Table 9. The values obtained from the confirmatory experiments validated the optimized levels. The confirmatory run not only validated the reliability of the optimization step (results within $5 \%$ of the predicted value) but also ensured repeatability.

Table 9. Confirmation experiment.

\begin{tabular}{ccccc}
\hline $\begin{array}{c}\text { Performance } \\
\text { Characteristics }\end{array}$ & $\begin{array}{c}\text { Optimal Values from } \\
\text { (Design Matrix) }\end{array}$ & $\begin{array}{c}\text { Predicted } \\
\text { Values }\end{array}$ & $\begin{array}{c}\text { Confirmatory } \\
\text { Experiment Values }\end{array}$ & $\begin{array}{c}\text { \%Age Error of } \\
\text { Confirmatory Values }\end{array}$ \\
\hline IT $(\mu \mathrm{m})$ & 42.0 & 41.20 & 43.2 & 4.85 \\
H $(\mathrm{GPa})$ & 10.76 & 10.76 & 10.84 & 0.74 \\
Cooling Rate & 2.12 & 2.14 & 2.14 & - \\
\hline
\end{tabular}

It is important to mention that the overall GRG analysis yields the following regression expression shown in Equation (7).

$$
\begin{aligned}
G R G=0.5993 & -0.1738 \mathrm{~T}\left({ }^{\circ} \mathrm{C}\right) \_800-0.0441 \mathrm{~T}\left({ }^{\circ} \mathrm{C}\right) \_850 \\
& +0.2178 \mathrm{~T}\left({ }^{\circ} \mathrm{C}\right) \_900-0.1286 \mathrm{P}(\mathrm{bar}) \_10 \\
& -0.0136 \mathrm{P}(\mathrm{bar}) \_15+0.1422 \mathrm{P}(\mathrm{bar}) \_20 \\
& +0.0094 \mathrm{Ht}(\mathrm{Sec}) \_10+0.0137 \mathrm{Ht}(\mathrm{Sec}) \_15 \\
& -0.0231 \mathrm{Ht}(\mathrm{Sec}) \_20 \pi r^{2}
\end{aligned}
$$

The samples from the optimum combination of input values were further tested for nano-cyclic loading conditions with a maximum applied load of $200 \mathrm{mN}$. The purpose 
of applying a cyclic load at the interface was to evaluate the interface developed for deformation under dynamic loading conditions. When a cyclic load is applied on the metallic materials in the plastic range, the tendency to resist deformation is different as compared to a continuous load [68]. It can be seen from Figure 16 that the sample at the optimum conditions restricted penetration much more than the other with the worst experimental conditions. Due to the increase in pouring temperature and applied pressure, a uniform interface and associated properties resulted in higher hardness at the interface and correspondingly minimum penetration of the indenter.

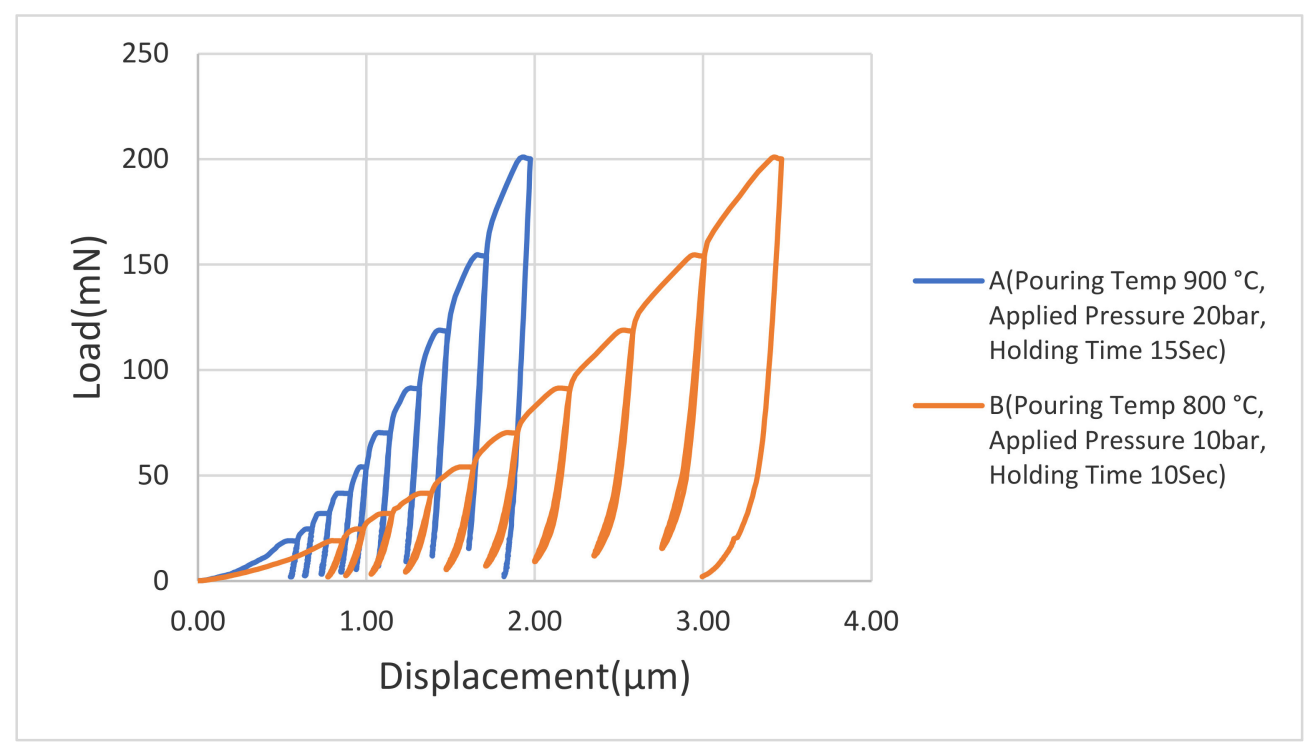

Figure 16. Load vs. displacement graph for cyclic loading.

\section{Conclusions and Recommendations}

In the context of developing aluminum-steel bimetallic composite castings via a pressure-assisted approach, the following conclusions may be drawn from the presented work:

- It is possible to generate uniform interfaces in a low-pressure regime of 10-20 bar. The successful utilization of a low-pressure regime for this purpose is expected to overcome the issues typically encountered in a high-pressure route, such as tool life, cost, handling of design complexity and unwanted reactions, etc.

- Analysis of variance (ANOVA) shows the pouring temperature is the most significant parameter for interface thickness and nano-indentation, whereas pressure comes out to be the most significant parameter for the cooling rate at a $95 \%$ confidence level.

- The mechanical characterization of the interface in terms of nano-indentation tests reveals the development of harder interfaces in comparison to the base constituents. This is attributed to the presence of brittle and harder intermetallic phases within the interface.

- Multi-objective optimization using GRA shows the highest grey relational grade (GRG) for Experiment 9's conditions (temperature $900^{\circ} \mathrm{C}$, pressure $20 \mathrm{bar}$ and holding time $15 \mathrm{~s}$ ), at which interface thickness of 42 microns and nano-indentation of $10.76 \mathrm{GPa}$ was achieved.

- The optimized parameters produced interfaces with higher nano-hardness not only for static loading but also for dynamic loading (when compared to the least values of the parametric combination). 
Author Contributions: T.R. conducted the experiments and performed measurements and analysis. M.Q.S. helped conceptualize the research plan, supervised the work and assisted in writing the article. N.A.M. modified the article structure and contributed to the analysis and discussion. N.A. and M.K.I. helped in statistical analysis and data interpretation. M.N. helped in analysis and discussion. All authors have read and agreed to the published version of the manuscript.

Funding: Not applicable.

Institutional Review Board Statement: Not applicable.

Informed Consent Statement: Not Applicable.

Data Availability Statement: Not applicable.

Acknowledgments: This work has been facilitated by the University of Engineering and Technology (UET), Lahore, Pakistan, as part of the post-graduate Ph.D. research work at the Department of Industrial and Manufacturing Engineering (UET) Lahore, Pakistan.

Conflicts of Interest: The authors declare that they have no conflict of interest.

\section{References}

1. Han, Q. A Modified Cast-on Method for the Reinforcement of Aluminum Castings with Dissimilar Metals. Metall. Mater. Trans. B Process. Metall. Mater. Process. Sci. 2016, 47, 3266-3273. [CrossRef]

2. Miyamoto, K.; Nakagawa, S.; Sugi, C.; Tsushima, K.; Iwatani, S.; Hojo, S.; Ogura, T.; Hirose, A.; Kobayashi, F.K. Dissimilar metals joining of steel and aluminum alloy by resistance spot welding-Dissimilar metals joining of steel and aluminum alloy by $\mathrm{Zn}$ insertion. J. Jpn. Weld. Soc. 2014, 32, 83-94. [CrossRef]

3. Kim, Y.M.; Choi, S.W.; Kim, Y.C.; Hong, S.K.; Kang, D.S.; Moon, M.K. Effects of die steel on die soldering of aluminum alloy die casting. Mater. Sci. Forum 2017, 879, 943-947. [CrossRef]

4. Shankar, S.; Apelian, D. Mechanism and preventive measures for die soldering during Al casting in a ferrous mold. JOM 2002, 54, 47-54. [CrossRef]

5. Han, Q.; Viswanathan, S. Analysis of the mechanism of die soldering in aluminum die casting. Metall. Mater. Trans. A 2003, 34, 139-146. [CrossRef]

6. Han, Q.; Kenik, E.A.; Viswanathan, S. Die soldering in aluminum die casting. In Light Metals, Proceedings of the 129th TMS Annual Meeting, Nashville, TN, USA, 12-16 March 2000; The Minerals, Metals \& Materials Society: Warrendale, PA, USA, 2000; pp. 765-770.

7. Ceschini, L.; Morri, A.; Toschi, S.; Bjurenstedt, A.; Seifeddine, S. Influence of sludge particles on the fatigue behavior of Al-Si-Cu secondary aluminium casting alloys. Metals 2018, 8, 268. [CrossRef]

8. Shabestari, S.G. The effect of iron and manganese on the formation of intermetallic compounds in aluminum-silicon alloys. Mater. Sci. Eng. A 2004, 383, 289-298. [CrossRef]

9. Dinnis, C.M.; Taylor, J.A.; Dahle, A.K. As-cast morphology of iron-intermetallics in Al-Si foundry alloys. Scr. Mater. 2005, 53, 955-958. [CrossRef]

10. Ma, Z.; Samuel, A.M.; Samuel, F.H.; Doty, H.W.; Valtierra, S. A study of tensile properties in Al-Si-Cu and Al-Si-Mg alloys: Effect of $\beta$-iron intermetallics and porosity. Mater. Sci. Eng. A 2008, 490, 36-51. [CrossRef]

11. Seifeddine, S.; Svensson, I.L. Prediction of mechanical properties of cast aluminium components at various iron contents. Mater. Des. 2010, 31, 6-12. [CrossRef]

12. Lemmens, B.; Springer, H.; De Graeve, I.; De Strycker, J.; Raabe, D.; Verbeken, K. Surface \& Coatings Technology Effect of silicon on the microstructure and growth kinetics of intermetallic phases formed during hot-dip aluminizing of ferritic steel. Surf. Coat. Technol. 2017, 319, 104-109. [CrossRef]

13. Deqing, W. Phase evolution of an aluminized steel by oxidation treatment. Appl. Surf. Sci. 2008, 254, 3026-3032. [CrossRef]

14. Kobayashi, S.; Yakou, T. Control of intermetallic compound layers at interface between steel and aluminum by diffusion-treatment. Mater. Sci. Eng. A 2002, 338, 44-53. [CrossRef]

15. Sasaki, T.; Yakou, T. Features of intermetallic compounds in aluminized steels formed using aluminum foil. Surf. Coat. Technol. 2006, 201, 2131-2139. [CrossRef]

16. Soderhjelm, C. Multi-Material Metal Casting: Metallurgically Bonding Aluminum to Ferrous Inserts; Worcester Polytechnic Institute: Worcester, MA, USA, 2017.

17. Beals, R.; Conklin, J.; Skszek, T.; Zaluzec, M.; Wagner, D. Aluminum High Pressure Vacuum Die Casting Applications for the Multi Material Lightweight Vehicle Program (MMLV) Body Structure. In Light Metals; Springer: Cham, Switzerland, 2015; Volume 2.

18. Akbarifar, M.; Divandari, M. Study of Al/cast iron interface and graphite behavior. J. Min. Met. Sect. B Met. 2017, 53, 53-59. [CrossRef]

19. Viala, J.; Peronnet, M.; Barbeau, F.; Bosselet, F.; Bouix, J. Interface chemistry in aluminium alloy castings reinforced with iron base inserts. Compos. Part A Appl. Sci. Manuf. 2002, 33, 1417-1420. [CrossRef] 
20. Bhagat, R. High pressure squeeze casting of stainless steel wire reinforced aluminium matrix composites. Composites 1988, 19, 393-399. [CrossRef]

21. Ferro, P.; Fabrizi, A.; Bonollo, F.; Berto, F. Microstructural and mechanical characterization of a stainless-steel wire mesh-reinforced al-matrix composite. Frat. Integrita Strutt. 2021, 15, 289-301. [CrossRef]

22. Liu, T.; Wang, Q.; Sui, Y.; Wang, Q.; Ding, W. An investigation into aluminum-aluminum bimetal fabrication by squeeze casting. Mater. Des. 2015, 68, 8-17. [CrossRef]

23. Yue, T.M.; Chadwick, G.A. Squeeze casting of light alloys and their composites. J. Mater. Process. Technol. 1996, 58, 302-307. [CrossRef]

24. Jahangiri, A.; Marashi, S.P.H.; Mohammadaliha, M.; Ashofte, V. The effect of pressure and pouring temperature on the porosity, microstructure, hardness and yield stress of AA2024 aluminum alloy during the squeeze casting process. J. Mater. Process. Technol. 2017, 245, 1-6. [CrossRef]

25. Maleki, A.; Niroumand, B.; Shafyei, A. Effects of squeeze casting parameters on density, macrostructure and hardness of LM13 alloy. Mater. Sci. Eng. A 2006, 428, 135-140. [CrossRef]

26. Niu, X.P.; Hu, B.H.; Pinwill, I.; Li, H. Vacuum assisted high pressure die casting of aluminium alloys. J. Mater. Process. Technol. 2000, 105, 119-127. [CrossRef]

27. Aweda, J.O.; Adeyemi, M.B. Experimental determination of heat transfer coefficients during squeeze casting of aluminium. $J$. Mater. Process. Technol. 2009, 209, 1477-1483. [CrossRef]

28. Dhanashekar, M.; Senthil Kumar, V.S. Squeeze casting of aluminium metal matrix composites-An overview. Procedia Eng. 2014, 97, 412-420. [CrossRef]

29. Liu, T.; Wang, Q.; Sui, Y.; Wang, Q.; Ding, W. An investigation into interface formation and mechanical properties of aluminumcopper bimetal by squeeze casting. Mater. Des. 2016, 89, 1137-1146. [CrossRef]

30. Alhashmy, H.A.; Nganbe, M. Laminate squeeze casting of carbon fiber reinforced aluminum matrix composites. Mater. Des. 2015, 67, 154-158. [CrossRef]

31. Liu, T.; Wang, Q.; Sui, Y.; Wang, Q. Microstructure and Mechanical Properties of Overcast 6101-6101 Wrought Al Alloy Joint by Squeeze Casting. J. Mater. Sci. Technol. 2016, 32, 298-304. [CrossRef]

32. Bouayad, A.; Gerometta, C.; Radouani, M.; Saka, A. Interface Characterization in Aluminum Alloy Casting Reinforced with SG Iron Inserts. Mech. Eng. 2010, 1, 226-231.

33. Ghomashchi, M.R.; Vikhrov, A. Squeeze casting: An overview. J. Mater. Process. Technol. 2000, 101, 1-9. [CrossRef]

34. Kapranos, P.; Carney, C.; Pola, A.; Jolly, M. Advanced Casting Methodologies: Investment Casting, Centrifugal Casting, Squeeze Casting, Metal Spinning, and Batch Casting; Elsevier: Amsterdam, The Netherlands, 2014; Volume 5, ISBN 9780080965338.

35. Kainer, K.U.; Benzler, T.U. Squeeze-casting and thixo-casting of magnesium alloys. In Magnesium-Alloys Technology; Wiley-VCH: Weinheim, Germany, 2004; pp. 56-71. [CrossRef]

36. Deng, J. Introduction to Grey System Theory. J. Grey Syst. 1989, 1, 1-24.

37. Awan, G.H.; Hasan, F.U. The morphology of coating/substrate interface in hot-dip-aluminized steels. Mater. Sci. Eng. A 2008, 472, 157-165. [CrossRef]

38. Deqing, W.; Ziyuan, S.; Longjiang, Z. A liquid aluminum corrosion resistance surface on steel substrate. Appl. Surf. Sci. 2003, 214, 304-311. [CrossRef]

39. Patel, G.C.M.; Krishna, P.; Parappagoudar, M.B. Optimization of Squeeze Cast Process Parameters Using Taguchi and Grey Relational Analysis. Procedia Technol. 2014, 14, 157-164. [CrossRef]

40. Adke, M.N. Optimization of die-casting process parameters to identify optimized level for cycle time using Taguchi method. Int. J. Innov. Eng. Technol. 2014, 4, 365-375.

41. Apparao, K.C.; Birru, A.K. Optimization of die casting process based on Taguchi approach. Mater. Today Proc. 2017, 4, 1852-1859. [CrossRef]

42. Rafidah, A.; Nurulhuda, A.; Azrina, A.; Suhaila, Y.; Anwar, I.S.; Syafiq, R.A. Comparison design of experiment (DOE): Taguchi method and full factorial design in surface roughness. Appl. Mech. Mater. 2014, 660, 275-279. [CrossRef]

43. Adke, M.N.; Karanjkar, S. V Optimization of die-casting process parameters using DOE. Int. J. Eng. Res. Gen. Sci. 2015, 3, 1314-1325.

44. Zahoor, S.; Saleem, M.Q.; Abdul-Kader, W.; Ishfaq, K.; Shehzad, A.; Ghani, H.U.; Hussain, A.; Usman, M.; Dawood, M. Improving surface integrity aspects of AISI 316L in the context of bioimplant applications. Int. J. Adv. Manuf. Technol. 2019, 105, $2857-2867$. [CrossRef]

45. Sylajakumari, P.A.; Ramakrishnasamy, R.; Palaniappan, G. Taguchi grey relational analysis for multi-response optimization of wear in co-continuous composite. Materials 2018, 11, 1743. [CrossRef]

46. Daniel, S.A.A.; Pugazhenthi, R.; Kumar, R.; Vijayananth, S. Multi objective prediction and optimization of control parameters in the milling of aluminium hybrid metal matrix composites using ANN and Taguchi -grey relational analysis. Def. Technol. 2019, 15, 545-556. [CrossRef]

47. Qazi, M.I.; Akhtar, R.; Abas, M.; Khalid, Q.S.; Babar, A.R.; Pruncu, C.I. An integrated approach of GRA coupled with principal component analysis for multi-optimization of shielded metal arc welding (SMAW) process. Materials 2020, 13, 3457. [CrossRef] [PubMed] 
48. Maleki, A.; Teimouri, R. Optimization of ultrasonic nanocrystalline surface modification of copper and its influence on fatigue life. Int. J. Light. Mater. Manuf. 2021, 4, 156-164. [CrossRef]

49. Callister, W.D., Jr.; Rethwisch, D.G. Materials Science and Engineering-An Introduction, 10th ed.; Ratts, L., Alecci, A., Giattino, A., Eds.; John Wiley \& Sons: Hoboken, NJ, USA, 2018; ISBN 9781119321590.

50. Chen, G.; Chang, X.; Liu, G.; Chen, Q.; Han, F.; Zhang, S.; Zhao, Z. Formation of metallurgical bonding interface in aluminum-steel bimetal parts by thixotropic-core compound forging. J. Mater. Process. Technol. 2020, 283, 116710. [CrossRef]

51. Jiang, W.; Fan, Z.; Li, C. Improved steel/aluminum bonding in bimetallic castings by a compound casting process. J. Mater. Process. Technol. 2015, 226, 25-31. [CrossRef]

52. Bakke, A.O.; Arnberg, L.; Løland, J.O.; Jørgensen, S.; Kvinge, J.; Li, Y. Formation and evolution of the interfacial structure in al/steel compound castings during solidification and heat treatment. J. Alloys Compd. 2020, 849, 156685. [CrossRef]

53. Shackelford, J.F. Introduction to Materials Science for Engineers, 8th ed.; Pearson: London, UK, 2009; ISBN 9780136012603.

54. Choe, K.H.; Park, K.S.; Kang, B.H.; Cho, G.S.; Kim, K.Y.; Lee, K.W.; Kim, M.H.; Ikenaga, A. Study of the Interface between Steel Insert and Aluminum Casting in EPC. J. Mater. Sci. Technol. 2008, 24, 60-64.

55. Srikumar Banerjee, P.M. Diffusional transformations. In Phase Transformations; Elsevier: Amsterdam, The Netherlands, 2007; Volume 12, Chapter 7; pp. 555-716. ISBN 9780080421452.

56. Jiang, W.; Jiang, H.; Li, G.; Guan, F.; Zhu, J.; Fan, Z. Microstructure, Mechanical Properties and Fracture Behavior of Magnesium/Steel Bimetal Using Compound Casting Assisted with Hot-Dip Aluminizing. Met. Mater. Int. 2020, 27, 2977-2988. [CrossRef]

57. Bouché, K.; Barbier, F.; Coulet, A. Intermetallic compound layer growth between solid iron and molten aluminium. Mater. Sci. Eng. A 1998, 249, 167-175. [CrossRef]

58. Jiang, W.; Fan, Z.; Li, G.; Liu, X.; Liu, F. Effects of hot-dip galvanizing and aluminizing on interfacial microstructures and mechanical properties of aluminum/iron bimetallic composites. J. Alloys Compd. 2016, 688, 742-751. [CrossRef]

59. Vendra, L.J.; Rabiei, A. A study on aluminum-steel composite metal foam processed by casting. Mater. Sci. Eng. A 2007, 465, 59-67. [CrossRef]

60. Mathew, J.; Remy, G.; Williams, M.A.; Tang, F.; Srirangam, P. Effect of Fe Intermetallics on Microstructure and Properties of Al-7Si Alloys. JOM 2019, 71, 4362-4369. [CrossRef]

61. Cao, X.; Zhou, X.; Li, Z.; Luo, Z.; Duan, J. Interface microstructure and nanoindentation characterization of laser offset welded 5052 aluminum to press-hardened steel using a brass interlayer. Metals 2019, 9, 1143. [CrossRef]

62. Wang, F.; Zhao, X.; Liu, J.; Ma, Q.; Sun, J.; Xu, S.; Han, Z. Study on the relationship between interfacial heat transfer coefficient and interface pressure in squeeze casting by using microscopic contact model. Int. J. Therm. Sci. 2020, 152, 106300. [CrossRef]

63. Wang, F.; Ma, Q.; Meng, W.; Han, Z. Experimental study on the heat transfer behavior and contact pressure at the casting-mold interface in squeeze casting of aluminum alloy. Int. J. Heat Mass Transf. 2017, 112, 1032-1043. [CrossRef]

64. Hajjari, E.; Divandari, M. An investigation on the microstructure and tensile properties of direct squeeze cast and gravity die cast 2024 wrought Al alloy. Mater. Des. 2008, 29, 1685-1689. [CrossRef]

65. Benjunior, B.; Ahmad, A.H.; Mohd, M.; Reza, M.S. Effect of Different Cooling Rates Condition on Thermal Profile and Microstructure of Aluminium 6061. Procedia Eng. 2017, 184, 298-305. [CrossRef]

66. Amin, K.M.; Mufti, N.A. Investigating cooling curve profile and microstructure of a squeeze cast Al-4\%Cu alloy. J. Mater. Process. Technol. 2012, 212, 1631-1639. [CrossRef]

67. Saleem, M.; Makhlouf, M. Helium-Assisted Sand Casting. Int. J. Met. 2012, 6, 43-59. [CrossRef]

68. Yang, F.; Peng, L.; Okazaki, K. Cyclic indentation in aluminum. J. Mater. Sci. 2007, 42, 4513-4520. [CrossRef] 